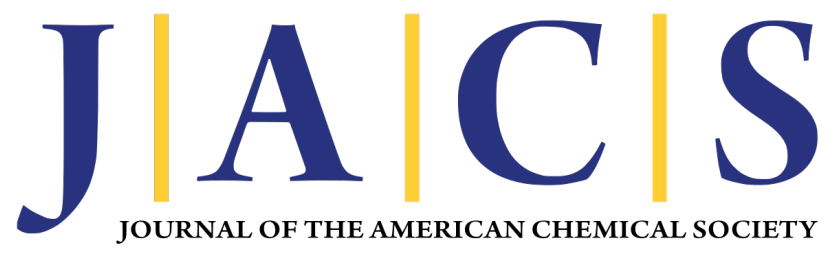

Supporting Information

\title{
How Radical are 'Radical' Photocatalysts? A Closed-Shell Meisenheimer Complex is Identified as a Super-reducing Photoreagent
}

Adam J. Rieth, Miguel I. Gonzalez, Bryan Kudisch, Matthew Nava, and Daniel G. Nocera* $^{*}$

Department of Chemistry and Chemical Biology, Harvard University, 12 Oxford Street, Cambridge, MA 02138

* Corresponding author email: dnocera@fas.harvard.edu 


\section{Table of Contents}

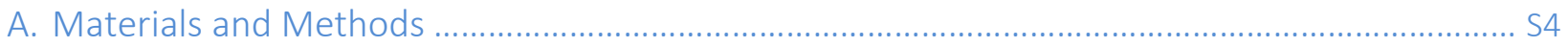

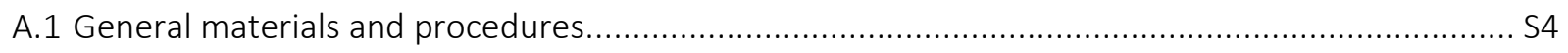

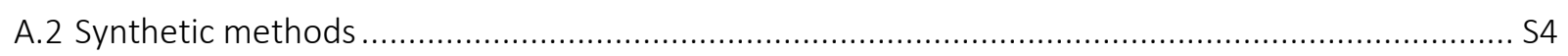

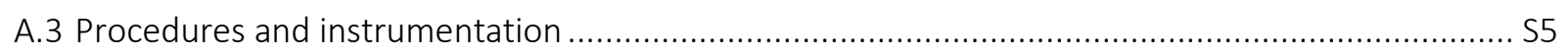

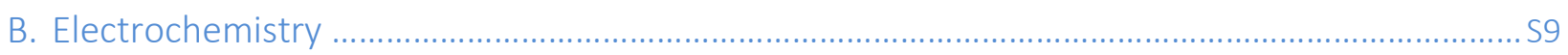

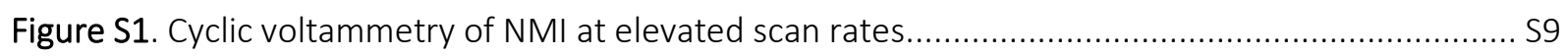

Figure S2. Scan rate dependance of peak currents in cyclic voltammetry of NMI ............................ S9

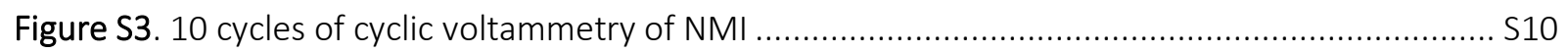

Figure S4. Potential window dependance of cyclic voltammetry of NMI .......................................... S10

Figure S5. Images of bulk electrolysis setups in a W-cell ................................................................. S11

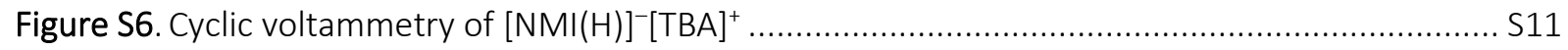

C. Steady-State and Time-Resolved Emission....................................................................... 112

Figure S7. Steady-state emission and excitation of electrolyzed and TBAF treated NMI samples ....... S12

Figure S8. Infrared emission and excitation of the radical anion of NMI electrolyzed at $-2.3 \mathrm{~V}$......... S12

Figure S9. Time-resolved emission lifetime fits for NMI treated with 4-methylchlorobenzoate .......... S13

Figure S10. Time-resolved emission lifetime fits for NMI treated with chlorobenzene ..................... S14

D. Nuclear Magnetic Resonance (NMR) Spectroscopy ........................................................... S15

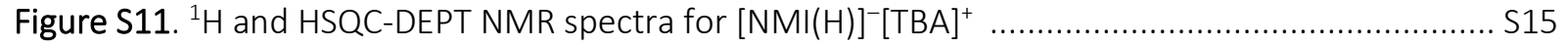

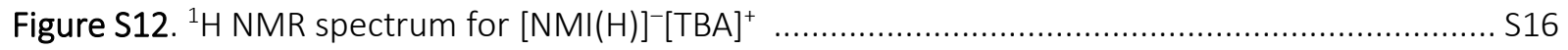

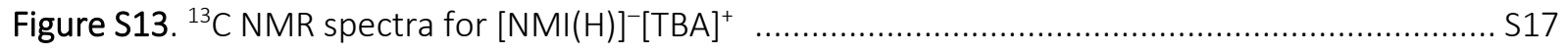

Figure S14. ${ }^{1} \mathrm{H}$ NMR spectra for NMI and partially deuterated NMI ......................................... S18

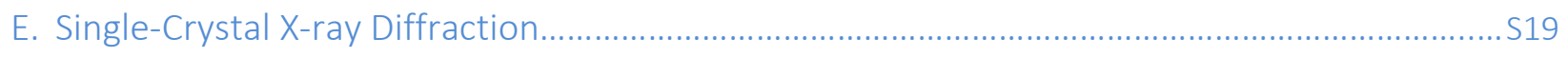

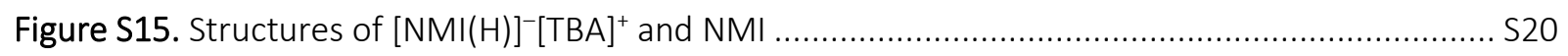

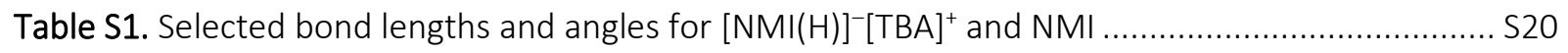

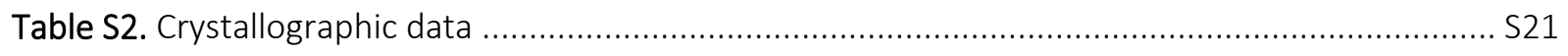

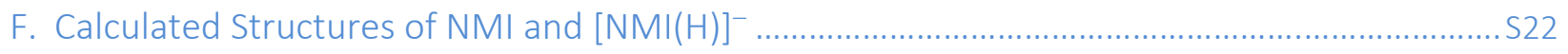

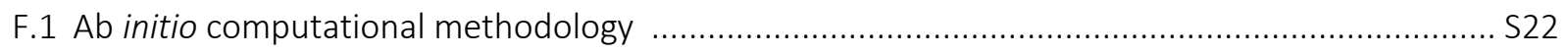

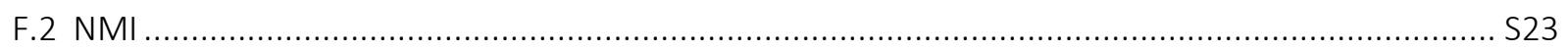

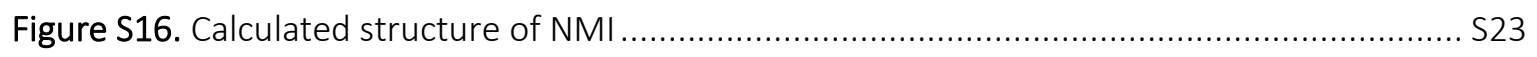

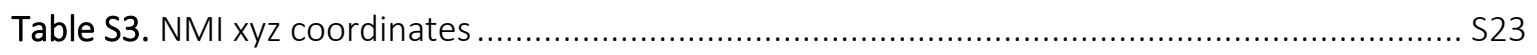

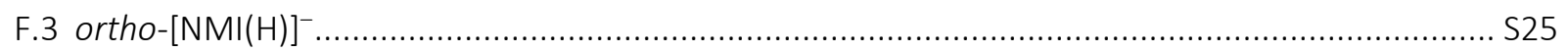

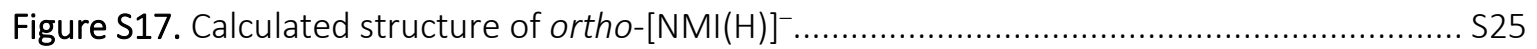

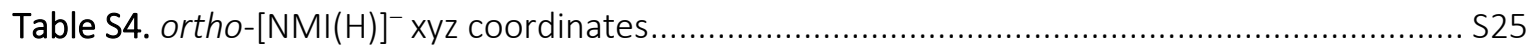

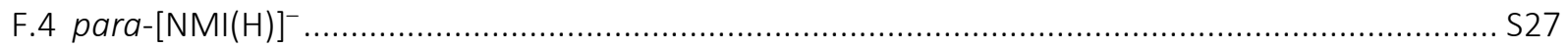




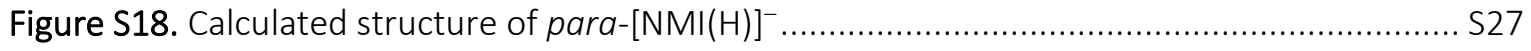

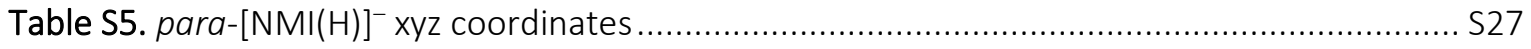

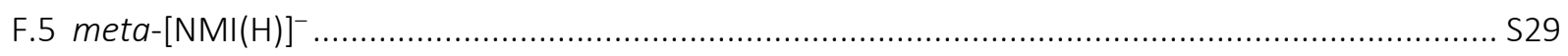

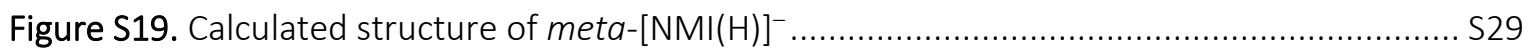

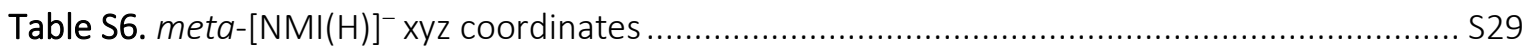

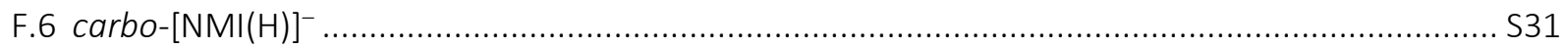

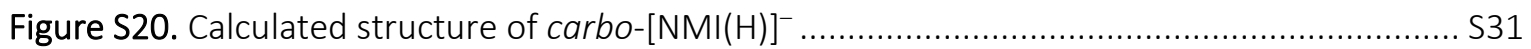

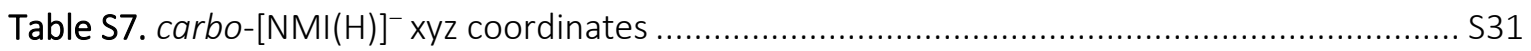

G. NMR Chemical Shift and Absolute Chemical Shielding Calculations ..................................... S33

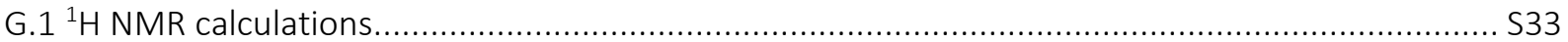

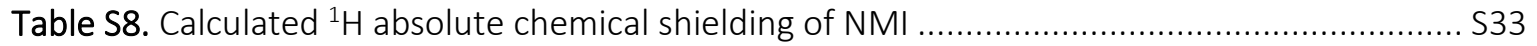

Figure S21. ${ }^{1} \mathrm{H}$ experimental shift versus absolute chemical shielding of NMI........................... S33

Table S9. Calculated ${ }^{1} \mathrm{H}$ absolute chemical shielding and predicted shift of ortho- $[\mathrm{NMI}(\mathrm{H})]^{-} \ldots \ldots . . \mathrm{S} 34$

Table S10. Calculated ${ }^{1} \mathrm{H}$ absolute chemical shielding and predicted shift of para-[NMI(H)]- $]^{-} \ldots . . . \mathrm{S} 34$

Table S11. Calculated ${ }^{1} \mathrm{H}$ absolute chemical shielding and predicted shift of meta-[NMI(H)] $]^{-}$..... S35

Table S12. Calculated ${ }^{1} \mathrm{H}$ absolute chemical shielding and predicted shift of carbo-[NMI(H)] $]^{-}$... S35

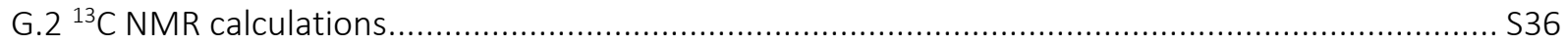

Table S13. Calculated ${ }^{13} \mathrm{C}$ absolute chemical shielding of NMI ............................................... S36

Figure S22. ${ }^{13} \mathrm{C}$ experimental shift versus absolute chemical shielding of NMI.......................... S37

Table S14. Calculated ${ }^{13} \mathrm{C}$ absolute chemical shielding and predicted shift of ortho-[NMI(H) $]^{-} \ldots . . \mathrm{S} 37$

Table S15. Calculated ${ }^{13} \mathrm{C}$ absolute chemical shielding and predicted shift of para- $[\mathrm{NMI}(\mathrm{H})]^{-}$...... S37

Table S16. Calculated ${ }^{13} \mathrm{C}$ absolute chemical shielding and predicted shift of meta-[NMI(H)]- .... S38

Table S17. Calculated ${ }^{13} \mathrm{C}$ absolute chemical shielding and predicted shift of carbo- $[\mathrm{NMI}(\mathrm{H})]^{-} \ldots \mathrm{S} 38$

G.3 Analysis of the experimental NMR spectra based on calculations ......................................... S38

Table S18. Calculated ${ }^{1} \mathrm{H}$ and ${ }^{13} \mathrm{C}$ shifts of hydridic positions for isomers of $[\mathrm{NMI}(\mathrm{H})]^{-} \ldots \ldots \ldots \ldots \ldots . . . . . . . .539$

Table S19. Experimental ${ }^{1} \mathrm{H}$ and ${ }^{13} \mathrm{C}$ shifts of hydridic positions for isomers of $[\mathrm{NMI}(\mathrm{H})]^{-} \ldots \ldots \ldots \ldots . \mathrm{S} 39$

Figure S23. Tentative isomer assignment of the ${ }^{1} \mathrm{H}$ NMR spectrum ...................................... S40

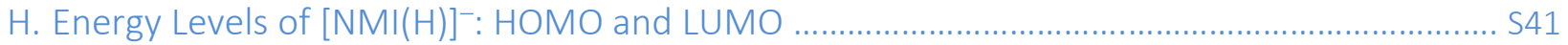

Figure S24. Assignment of $\mathrm{HOMO}$ and $E_{00}$ energies, and -[NMI(H)]- Latimer diagram ................. S41

I. Photoreactivity of $[\mathrm{NMI}(\mathrm{H})]^{-}[\mathrm{TBA}]^{+}$with Methyl-4-Chlorobenzoate .....................................S42

Figure S25. $[\mathrm{NMI}(\mathrm{H})]^{-}[\mathrm{TBA}]^{+}$and methyl-4-chlorobenzoate ${ }^{1} \mathrm{H}$ NMR spectra .......................... S43

Figure S26. [NMI $(\mathrm{H})]^{-}[\mathrm{TBA}]^{+}$, methyl-4-chlorobenzoate, and $\mathrm{N}$-methyl pyrrole ${ }^{1} \mathrm{H}$ NMR spectra .. S44

Figure S27. [NMI(H)] $\left.]^{-[T B A}\right]^{+}$, methyl-4-chlorobenzoate, and triethylphosphite ${ }^{1} \mathrm{H}$ NMR spectra.. S45

Figure S28. $[\mathrm{NMI}(\mathrm{H})]^{-}[\mathrm{TBA}]^{+}$, methyl-4-chlorobenzoate, and triethylphosphite ${ }^{31} \mathrm{P}$ NMR spectra. S46

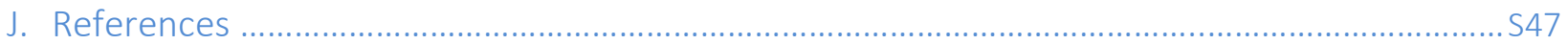




\section{A. Materials and Methods}

\section{A.1 General Materials and Procedures}

All reagents were purchased from commercial suppliers and used without further purification, unless otherwise noted. Solvents were purified by an argon purged solvent purification system and stored over activated 3-Å molecular sieves in a $\mathrm{N}_{2}$-filled glovebox, unless otherwise noted. Dimethylacetamide (DMAc) and propylene carbonate were purchased from Sigma Aldrich in Sure/Seal bottles and stored over activated $4-\AA \AA \AA$ molecular sieves in a $\mathrm{N}_{2}$-filled glovebox. All samples were prepared in a $\mathrm{N}_{2}$-filled glovebox.

\section{A.2 Synthetic Methods}

Naphthalene monoimide (NMI). NMI was synthesized as previously reported. ${ }^{1}$ Briefly, $6.73 \mathrm{~g}$ (34 $\mathrm{mmol}$ ) naphthalic anhydride was suspended in $100 \mathrm{~mL}$ propionic acid, then $19.0 \mathrm{~mL}$ (100 mmol) 2,6-diisopropylaniline was added. The mixture was stirred under nitrogen and heated to reflux overnight. After cooling to room temperature, $50 \mathrm{~mL}$ deionized water was added and solids were collected by filtration. The solids were washed with water, then hexanes, then dried at $50^{\circ} \mathrm{C}$. The solids were recrystallized from chloroform/hexanes to obtain white crystalline solids. A second recrystallization by slow diffusion of diethyl ether into dichloromethane was performed to obtain colorless plate crystals suitable for single-crystal X-ray diffraction.

Treatment with tetrabutylammonium fluoride (TBAF) in DMAc. Inside a $\mathrm{N}_{2}$-filled glovebox, NMI $(7.5 \mathrm{mg}$ ) was dissolved in $20 \mathrm{~mL}$ DMAc, then $0.2 \mathrm{~mL} 1 \mathrm{M}$ TBAF in tetrahydrofuran was added. The solution immediately turns orange and slowly darkens, with visible green emission.

Isolation of hydride-reduced [NMI(H)]-[TBA] +. Naphthalene monoimide (400 mg, 1.09 mmol) and $\mathrm{NaBH}_{4}(50 \mathrm{mg}, 1.31 \mathrm{mmol})$ were added to a $250 \mathrm{~mL}$ Schlenk flask with a stir bar and degassed by 5 vacuum/nitrogen cycles. The flask was then cooled in an ice water bath. Dimethoxyethane (DME) $(80 \mathrm{~mL}$ ) from an Ar-purged solvent purification system was then added to the flask via cannula transfer. The mixture was then stirred under nitrogen in the ice bath for $4 \mathrm{~h}$, over which time it slowly turned from clear to yellow to bright orange. The solution was allowed to warm to room temperature and stirred under nitrogen overnight. The solvent volume was reduced to 20 
$\mathrm{mL}$ under vacuum, then the flask was sealed under vacuum and brought into a nitrogen-filled glovebox. Hexanes $(100 \mathrm{~mL}$ ) was added and the resulting bright yellow precipitate was collected by filtration. The solids were washed with diethyl ether and then suspended and stirred overnight in $80 \mathrm{~mL}$ benzene with $600 \mathrm{mg}$ tetrabutylammonium chloride (TBACl) $(2.18 \mathrm{mmol})$. The solids were removed by filtration. The filtrate solvent volume was reduced by half under vacuum, and then $100 \mathrm{~mL}$ diethyl ether was added, and the resulting bright orange precipitate was collected by filtration and washed with ether. Crystals suitable for single-crystal X-ray diffraction were obtained by slow diffusion of diethyl ether into a toluene solution of the bright orange product.

Deuteration of NMI. In a $\mathrm{N}_{2}$-filled glovebox, naphthalene monoimide (200 mg, $0.545 \mathrm{mmol}$ ), $\mathrm{NaBD}_{4}$ (24 mg, $0.572 \mathrm{mmol}$ ), and tetrabutylammonium chloride (TBACl) (167 mg, $0.6 \mathrm{mmol}$ ) were added to a $20 \mathrm{~mL}$ vial with a stir bar. Dimethoxyethane (DME) $(20 \mathrm{~mL})$ from an Ar-purged solvent purification system, stored over 4A molecular sieves, was then added to the vial. The resulting solution was stirred for 6 hours, over which period it turned from clear to yellow to bright orange. The vial was then brought out of the glovebox and stirred open to air for 12 hours, after which point it had turned off-white, with some precipitate. The DME was evaporated under reduced pressure and the resulting off-white solids were dissolved in $20 \mathrm{~mL}$ dichloromethane (DCM) and washed with $3 \times 20 \mathrm{~mL} \mathrm{DI} \mathrm{H2O}$. The DCM solution was dried over $\mathrm{MgSO}_{4}$ and evaporated under reduced pressure, yielding white solids. ${ }^{1} \mathrm{H}$ NMR of the resulting solids was then obtained in $\mathrm{CDCl}_{3}$ (Figure S12).

\section{A.3 Procedures and Instrumentation}

UV-visible spectroscopy. Absorption spectroscopy was performed using a Varian Cary 5000 UVvis-NIR spectrometer

Electrochemistry and spectroelectrochemistry. Electrochemical experiments were performed using a $\mathrm{CH}$ Instruments 760D potentiostat in a nitrogen-filled glovebox. Cyclic voltammetry (CV) measurements were performed using a three-electrode setup with a glassy carbon or Platinum disk working electrode, a Pt mesh counter electrode, and a leak-free $\mathrm{Ag} / \mathrm{AgCl}$ reference electrode (Warner Instruments). Glassy carbon and platinum working electrodes were polished using 1- $\mu \mathrm{m}$ alumina powder on felt prior to use. After each CV, ferrocene (FC) was added and the CV was repeated to obtain an accurate non-aqueous reference. All compounds were dissolved in 
degassed propylene carbonate/0.1 M tetrabutylammonium hexafluorophosphate (electrochemical grade, Sigma Aldrich), which was stored on activated 4-A molecular sieves in the glovebox. Bulk electrolysis was performed in a W-cell with Pt wire working electrode and Pt mesh counter electrode with $1 \mathrm{mM} \mathrm{NMI}$ in the catholyte and $20 \mathrm{mM}$ triethylamine in the anolyte. Catholyte and anolyte compartments were stirred. Electrolysis was continued until the current was $10 \%$ of the initial value. For ultrafast transient absorption, the bulk-electrolyzed radical anion was diluted to an absorbance at $420 \mathrm{~nm}$ of 0.8 O.D.

Spectroelectrochemistry was performed using an OceanOptics USB400 spectrometer and DTmini-2-GS Deuterium/Halogen light source in an H-cell quartz cuvette using a Pt wire working electrode and a leak-free $\mathrm{Ag} / \mathrm{AgCl}$ reference electrode on the cuvette side, and a Pt mesh counter electrode on the opposite chamber, separated by a $1 \mathrm{~cm}^{2}$ glass frit. Approximately $20 \mathrm{mM}$ triethylamine was added to the counter electrode compartment.

Nuclear magnetic resonance (NMR). NMR experiments was performed in the Harvard University Department of Chemistry Laukien Purcell Instrumentation Facility using either a Bruker AVANCE NEO $400 \mathrm{MHz}$ spectrometer equipped with a broadband probe, a JEOL ECZ400S $400 \mathrm{MHz}$ spectrometer equipped with a broadband probe, or a Varian/Agilent DD2 $600 \mathrm{MHz}$ spectrometer equipped with a broadband probe.

Ultrafast transient absorption. The broadband femtosecond transient absorption setup is based on a previously reported single-shot probe-referenced design. ${ }^{2}$ The setup has been described in previous publications. A Ti:Sapphire regenerative amplifier (Coherent Libra-HE) provides $3 \mathrm{~W}$ fundamental pulses (800 nm, $\sim 50 \mathrm{fs}$ ) at $1 \mathrm{kHz}$. An OPerA SOLO (Coherent) is seeded with $2 \mathrm{~W}$ of the fundamental to provide pump pulses at $420 \mathrm{~nm}$. The pulse energy was set to $200 \mathrm{~nJ}$ using a variable neutral density filter. The pump pulses were subsequently aligned onto a $1.7 \mathrm{~m}$ computercontrolled, motorized translation stage (Aerotech ATS62150, U100 controller) equipped with a hollow retro-reflector (Newport) followed by an ultrabroadband polarizer and $\lambda / 2$ waveplate (Thorlabs) to produce linearly polarized pulses at magic angle $\left(54.7^{\circ}\right)$ with respect to the probe pulse. Alignment of the stage was confirmed immediately prior to the transient absorption experiments using a reference dye, $\mathrm{Ru}(\mathrm{bpy})_{3} \mathrm{Cl}_{2}$ in water, which when photoexcited under the same experimental conditions gave flat dynamics on the timescale investigated, in accordance with its excited state lifetime of greater than $7 \mathrm{~ns}$. 
Chirped white light pulses were generated by focusing a fraction ( $1 \mathrm{~mW}$ ) of the remaining fundamental laser output ( $f=100 \mathrm{~mm}$, Thorlabs) into a $5 \mathrm{~mm}$ calcium fluoride $\left(\mathrm{CaF}_{2}\right)$ crystal that was continuously translated back-and-forth perpendicular to the input beam to avoid thermal damage. The generated pulses were reflectively collimated ( $f=50 \mathrm{~mm}$, Thorlabs) and aligned onto a $15 \mathrm{~mm}$ translation stage (PhysikInstrumente, M-111.DG, Mercury DC controller). A notch filter (EKSMA, VEI6053) removed the residual fundamental and the white light pulses were subsequently sent onto a broadband reflective neutral density filter (Thorlabs, NDUV04B) to generate probe (reflected) and reference (transmitted) pulses of approximately equal intensity. Pump, probe, and reference pulses were reflectively focused into the sample $(f=200 \mathrm{~mm})$ to yield Gaussian beams with diameters (full-width-half-maximum) of $70 \mu \mathrm{m}$ (pump) and $40 \mu \mathrm{m}$ (probe/reference). At the sample position, a $2 \mathrm{~mm}$ quartz cuvette with a screwcap that had been verified to be air-tight housed the sample for measurement. The solution was stirred using a magnetic stirrer to combat sample degradation. The transmitted probe and reference pulses were subsequently collimated reflectively $(f=200 \mathrm{~mm}$ ) before being send into a home-built fused-silica prism (OptoSigma, DPSQ-20-10H) spectrograph ( $f=250 \mathrm{~mm}$ ) equipped with two 16 bit, 512 pixel charge-coupled devices (Hamamatsu S7030-0906). Data acquisition was enabled by a custombuild interface board from Entwicklungsbüro Stresing. Differential normalized transmittance signals were collected on shot-to-shot basis with the pump chopped at $500 \mathrm{~Hz}$.

A single transient absorption trace consisted of 200 collected probe shots, resulting in 100 differential spectra, which were averaged for each time point. Data presented in this study was obtained by recording 7 transient absorption traces and averaging the results; rapid sample degradation precluded further averaging. Kinetic data (Figure 3B) were obtained by averaging the intensities of the time-dependent data over several wavelengths: from 385-395 nm for the bleach feature and from 495-525 nm for the excited state absorption feature.

Steady-state emission spectra. Emission spectra were obtained using a fluorometer (Photon Technology International (PTI), Model QM4) equipped with a $150 \mathrm{~W}$ Xe arc lamp excitation source and a photomultiplier tube (PMT) detector. Infrared spectra (Figure S7) were measured using a PTI InGaAs detector. Samples were prepared in $1 \mathrm{~cm}$ quartz cuvettes with threaded caps in the glovebox. 
Time-resolved emission spectroscopy. Emission spectra with time resolution were collected using a Hamamatsu C4334 Streak Scope camera set perpendicular to the $480 \mathrm{~nm}$ excitation pulse, generated by a femtosecond noncollinear optical parametric amplifier (described above for transient absorption setup). For the streak scope, the blaze wavelength was $450 \mathrm{~nm}$, the grating was $100 \mathrm{~g} \mathrm{~mm}^{-1}$ the ruling was 100 , the slit width was 100 . The average of 5000 shots was used for each sample. There is no spectral correction for the streak camera, therefore the emission intensities appear slightly blue-shifted due to the blaze at $450 \mathrm{~nm}$, which is bluer than the measured emission from $550-600 \mathrm{~nm}$. The steady-state emission spectra are therefore a better representation of the emission intensities.

Dynamic Stern-Volmer quenching studies were carried out by measuring the lifetime $(\tau)$ by averaging the photon counts from $540-580 \mathrm{~nm}$ with excitation at $480 \mathrm{~nm}$. The quenching ratio $\left(\tau_{0} / \tau\right)$ and the Stern-Volmer constant $\left(K_{\mathrm{sv}}\right)$ were determined by the relation $\tau_{0} / \tau=1+$ $K_{\mathrm{sv}} \times$ [quencher], where $\tau_{\mathrm{o}}$ is the lifetime in the absence of quencher. The quenching rate $\left(k_{\mathrm{q}}\right)$ was determined by $k_{\mathrm{q}}=K_{\mathrm{sv}} / \tau_{\mathrm{o}}$. Samples were prepared in $1 \mathrm{~cm}^{2}$ quartz cuvettes with threaded caps in the glovebox.

Curve fitting was performed in OriginPro 9.0. Time-resolved emission data (Figures 3E, S8, S9) were fit according to a single exponential decay function $I(t)=I_{o} e^{-t / \tau_{o}}$. 


\section{B. Electrochemistry}

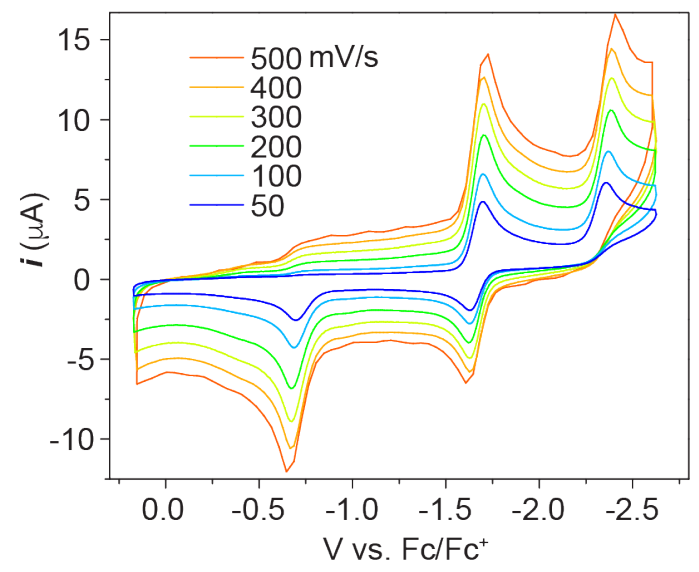

Figure S1. Cyclic voltammetry at scan rates from 50 to $500 \mathrm{mV} / \mathrm{s}$ of $1 \mathrm{mM} \mathrm{NMI}$ in $100 \mathrm{mM} \mathrm{TBAPF}_{6}$ propylene carbonate solution. Experiments were performed on a $1 \mathrm{~cm}^{2}$ glassy carbon working electrode, using a leakfree $\mathrm{Ag} / \mathrm{AgCl}$ reference electrode and a Pt mesh counter electrode in a $\mathrm{N}_{2}$-filled glovebox.
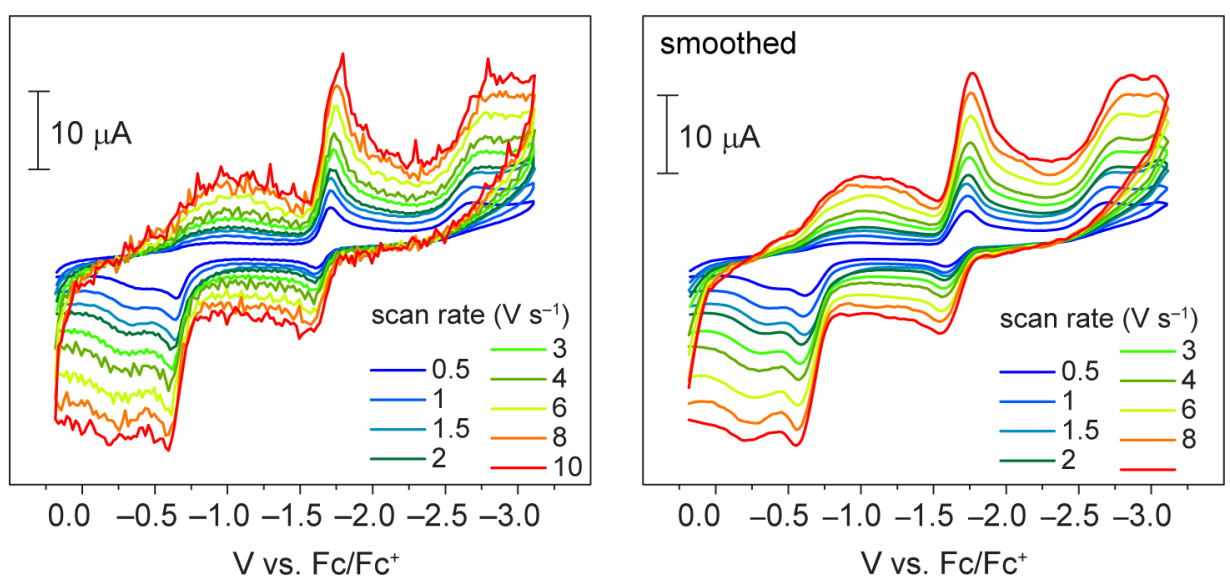

Figure S2. Cyclic voltammetry at elevated scan rates of $1 \mathrm{mM} \mathrm{NMI} \mathrm{in} 100 \mathrm{mM}$ TBAPF 6 propylene carbonate solution. Experiments were performed on a $0.5 \mathrm{~cm}^{2}$ Pt disk working electrode, using a leak-free $\mathrm{Ag} / \mathrm{AgCl}$ reference electrode and a Pt mesh counter electrode in a $\mathrm{N}_{2}$-filled glovebox. Left: raw data, Right: smoothed 


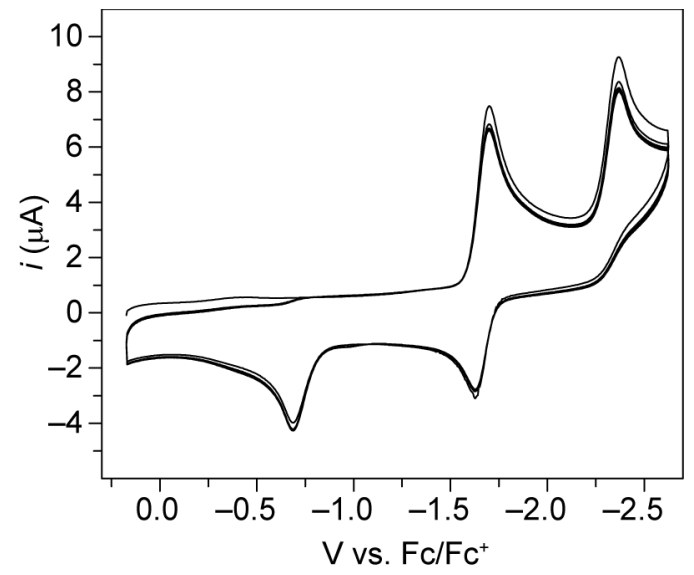

Figure S3. 10 cycles of cyclic voltammetry of $1 \mathrm{mM} \mathrm{NMI} \mathrm{in} 100$ mM TBAPF 6 propylene carbonate solution. The experiment was performed at $100 \mathrm{mV} \mathrm{s}^{-1}$ on a $1 \mathrm{~cm}^{2}$ glassy carbon working electrode, using a leak-free $\mathrm{Ag} / \mathrm{AgCl}$ reference electrode and a Pt mesh counter electrode in a nitrogen-filled glovebox.

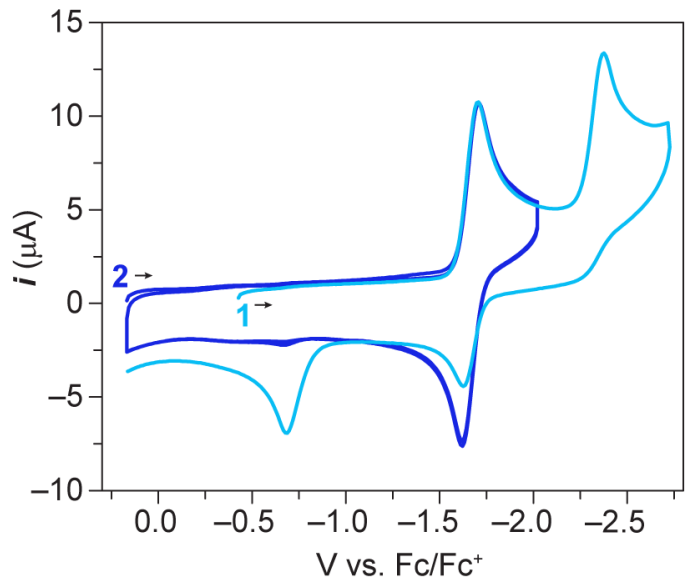

Figure S4. Cyclic voltammetry of $1 \mathrm{mM} \mathrm{NMI} \mathrm{in} 100 \mathrm{mM} \mathrm{TBAPF}_{6}$ propylene carbonate solution. After scanning past the second reductive feature on the first cycle (light blue), the sweep window was limited to $-2 \mathrm{~V}$ for the next 2 cycles (dark blue). The experiment was performed at $200 \mathrm{mV} \mathrm{s}^{-1}$ on a $1 \mathrm{~cm}^{2}$ glassy carbon working electrode, using a leak-free $\mathrm{Ag} / \mathrm{AgCl}$ reference electrode and a Pt mesh counter electrode in a nitrogenfilled glovebox. 


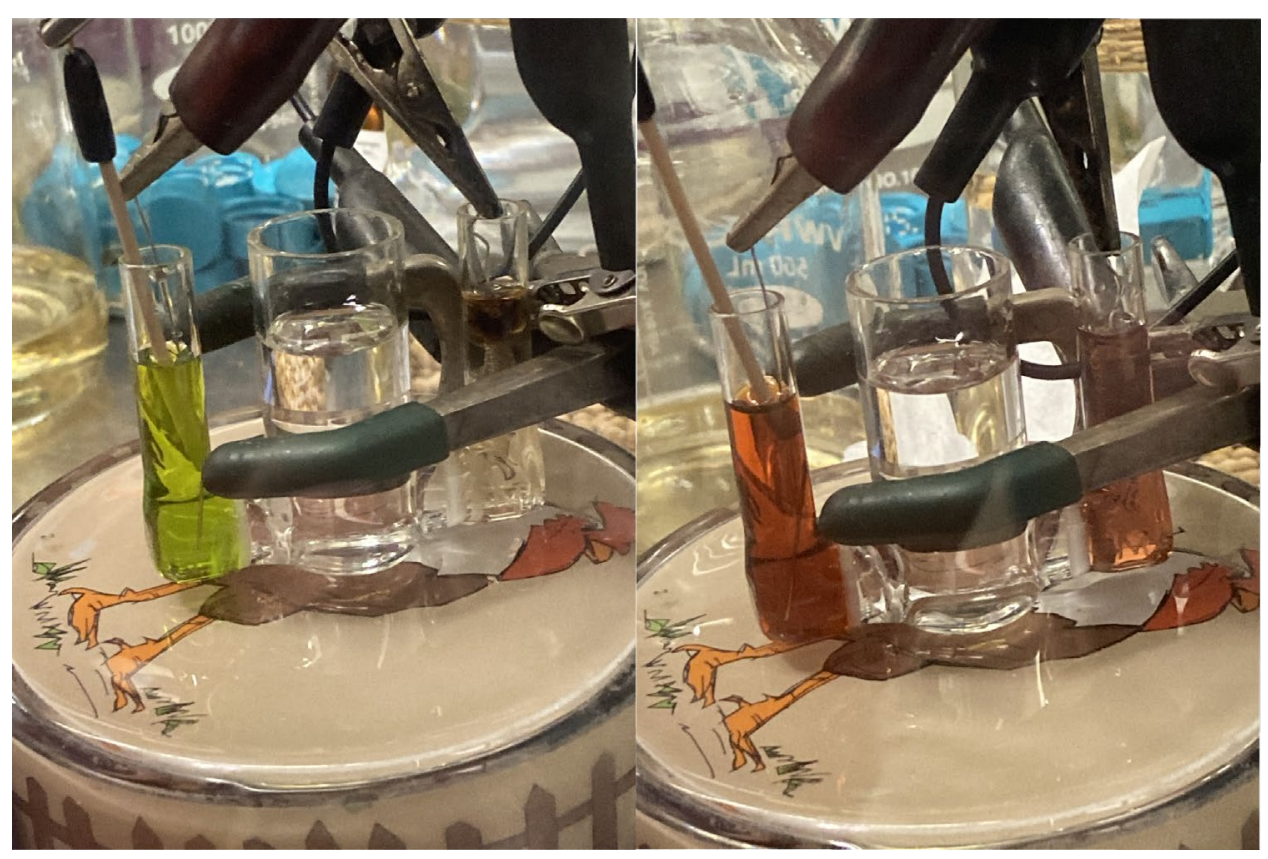

Figure S5. Setup for bulk electrolysis at $-2.3 \mathrm{~V}$ vs. $\mathrm{Fc} / \mathrm{Fc}^{+}$(left) and $-3 \mathrm{~V}$ vs. $\mathrm{Fc} / \mathrm{Fc}^{+}$(right) in a $\mathrm{W}$-cell inside a nitrogen-filled glovebox. TEA was used as a sacrificial reductant in the counter electrode compartment (right side of W-cell).

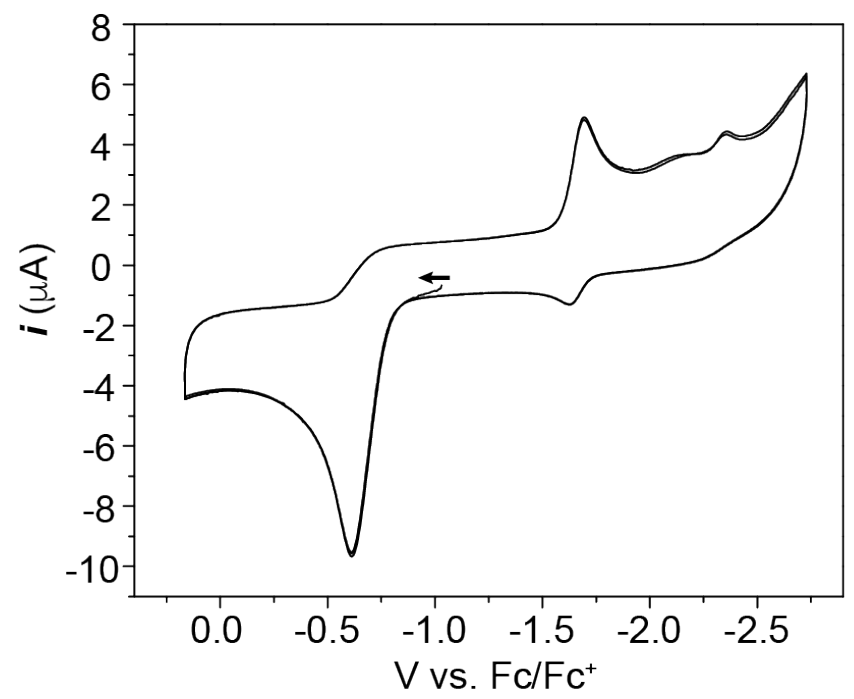

Figure S6. 3 cycles of cyclic voltammetry of $1 \mathrm{mM}[\mathrm{NMI}(\mathrm{H})]^{-}[\mathrm{TBA}]^{+}$in $100 \mathrm{mM}$ TBAPF$_{6}$ propylene carbonate solution. The experiment was performed at $100 \mathrm{mV} \mathrm{s}^{-1}$ on a $1 \mathrm{~cm}^{2}$ glassy carbon working electrode, using a leak-free $\mathrm{Ag} / \mathrm{AgCl}$ reference electrode and a Pt mesh counter electrode in a nitrogen-filled glovebox. 


\section{Steady-State and Time-Resolved Emission}
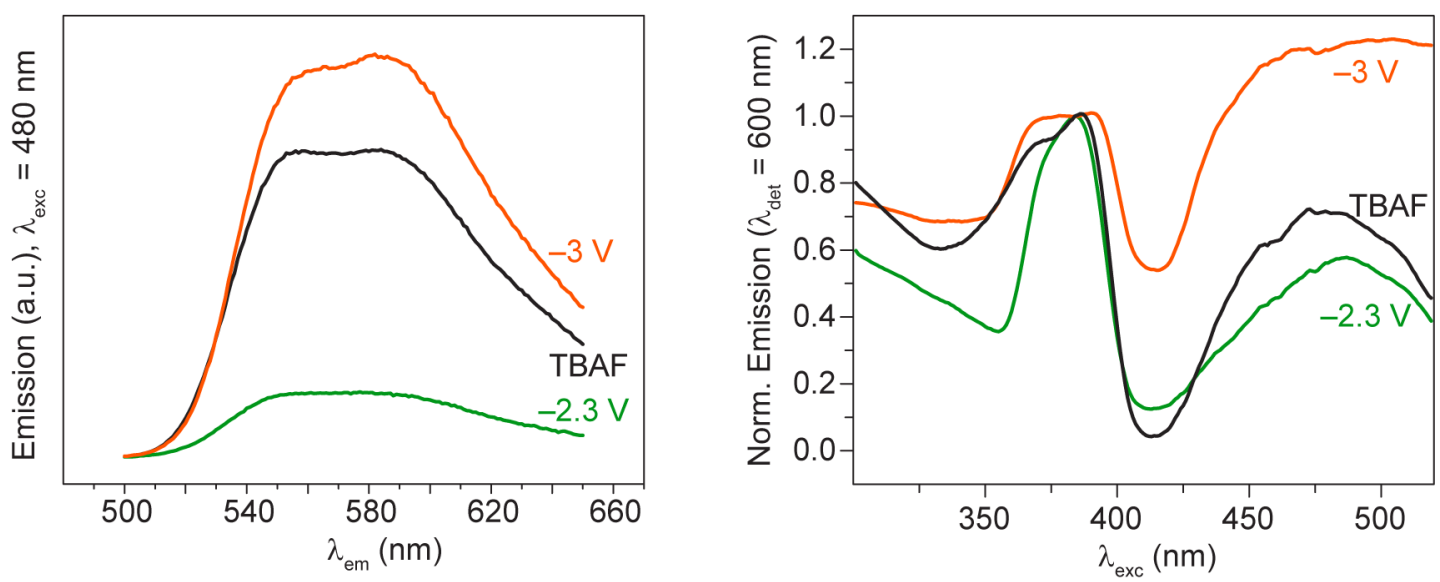

Figure S7. Emission (left) and excitation (right) spectra of NMI solutions electrolyzed at either -3.0 V (orange) or $-2.3 \mathrm{~V}$ (green) vs. Fc/Fc', compared with NMI treated with TBAF in DMAc (black). Grating corrections resulted in baseline deviations for excitation scans.
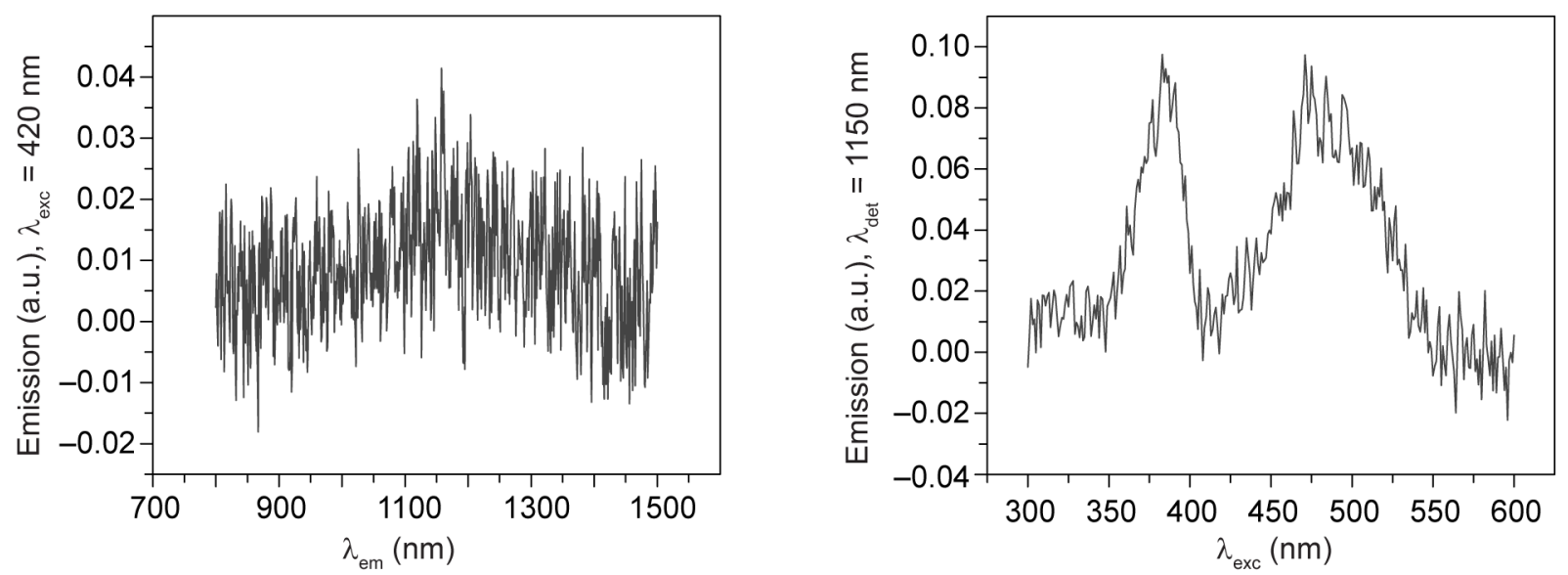

Figure S8. Infrared emission (left) and excitation (right) spectra of the NMI solution electrolyzed at or -2.3 $\mathrm{V}$ vs. $\mathrm{Fc} / \mathrm{Fc}^{+}$. Emission at $1150 \mathrm{~nm}$ is a second-order wavelength, at half the energy of the 550-600 nm emission in Figure $\mathrm{S6}$, and therefore arises from the two-electron reduced NMI, with an excitation spectrum matching the absorbance of the 2-electron-reduced species. No emission could be detected originating from the NMI radical anion. 

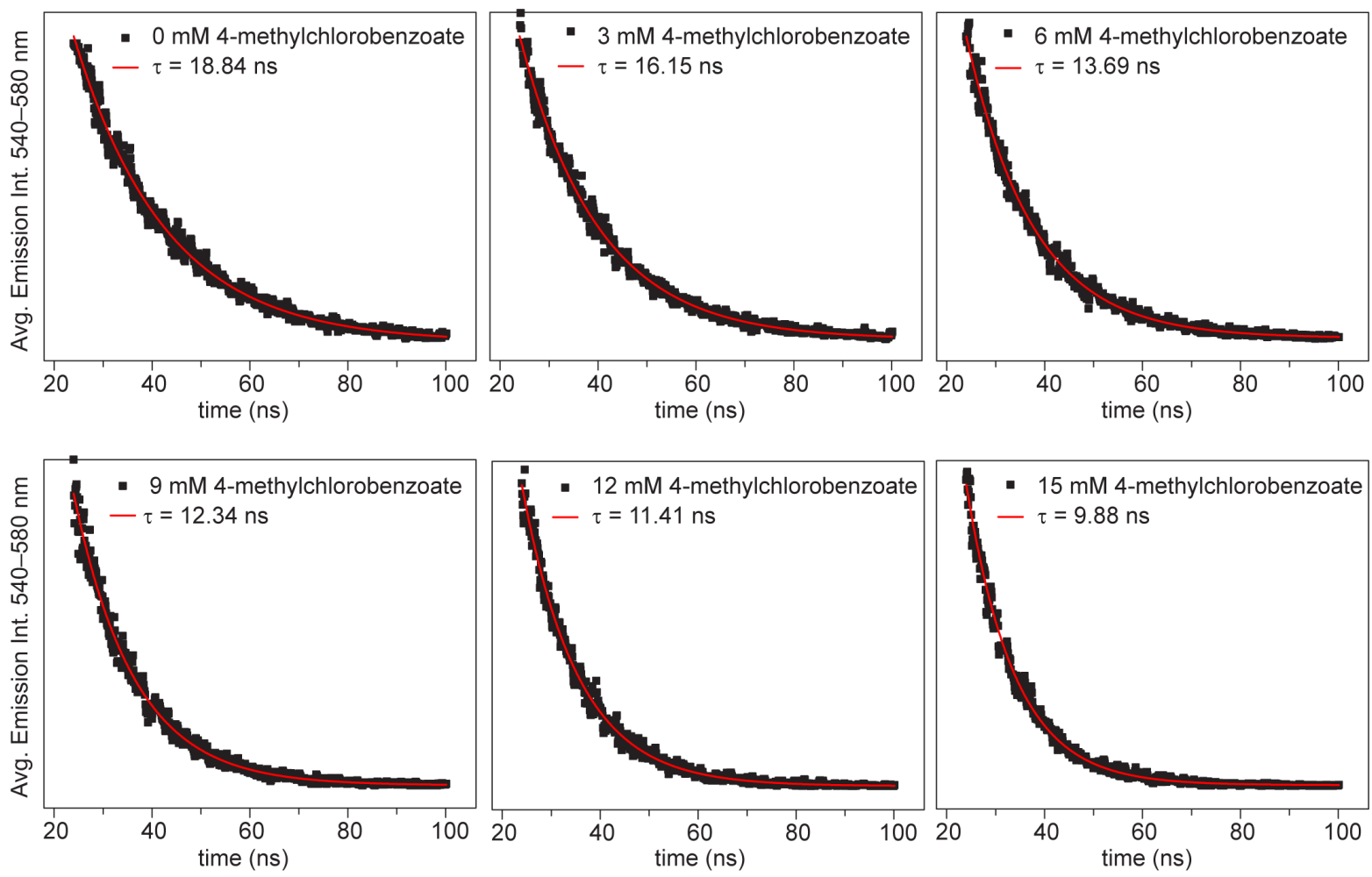

Figure S9. Time-resolved emission intensity $\left(\lambda_{\text {det }}=440-480 \mathrm{~nm}\right)$ with increasing concentration of 4methylchlorobenzoate. All samples are $0.1 \mathrm{mM} \mathrm{NMI}$ in $1 \mathrm{mM}$ TBAF in DMAc. Red lines are singleexponential decay fits to the data according to the equation $I(t)=I_{o} e^{-t / \tau}$. Stern-Volmer plot using this data presented in Figure 3F. 

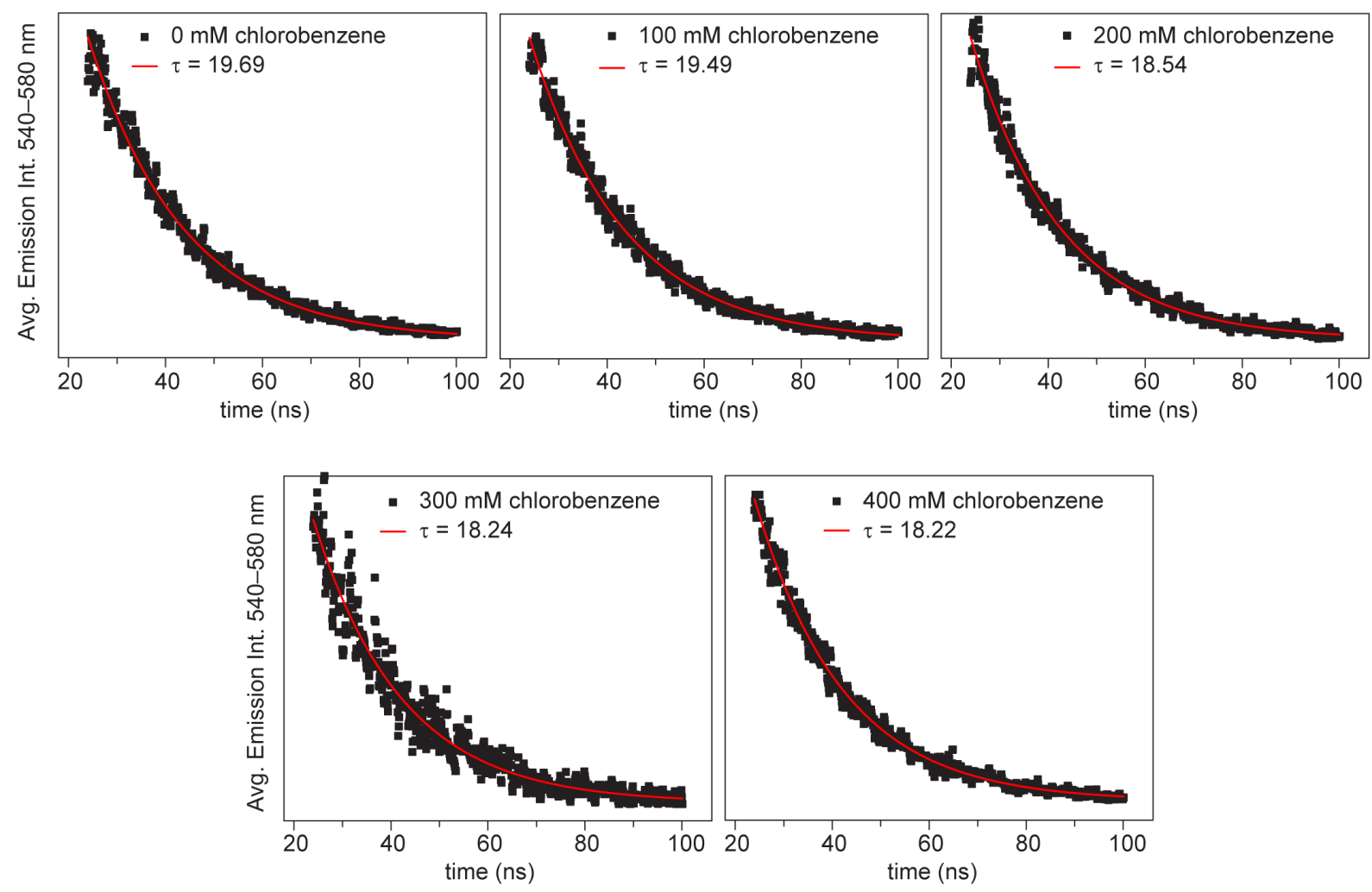

Figure S10. Time-resolved emission intensity $\left(\lambda_{\text {det }}=440-480 \mathrm{~nm}\right)$ with increasing concentration of chlorobenzene All samples are $0.1 \mathrm{mM} \mathrm{NMI}$ in $1 \mathrm{mM} \mathrm{TBAF}$ in DMAc. Red lines are single-exponential decay fits to the data according to the equation $I(t)=I_{o} e^{-t / \tau}$. Stern-Volmer plot using this data presented in Figure 3F. 


\section{NMR Spectroscopy}
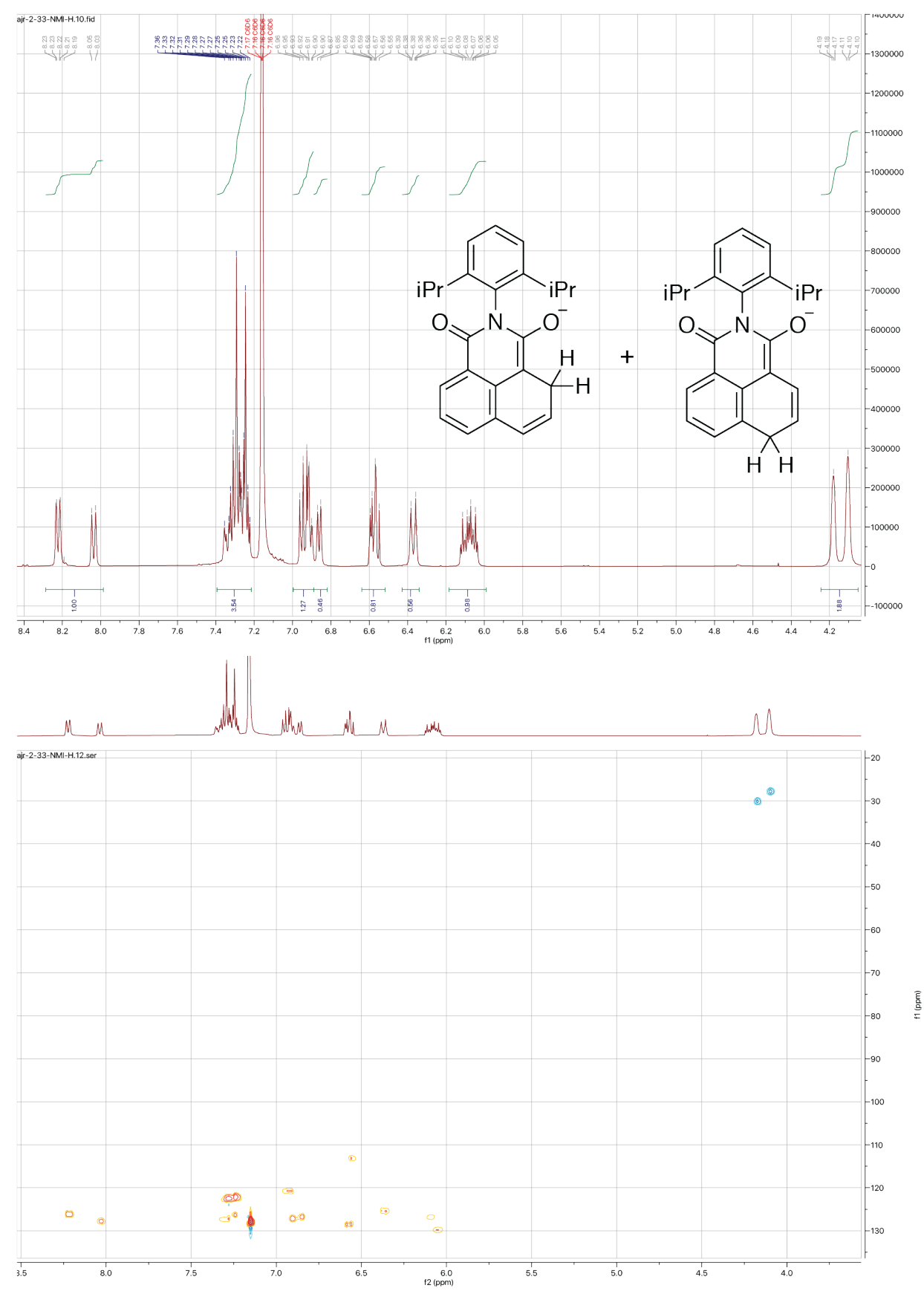

Figure S11. ${ }^{1} \mathrm{H}$ (top) and Heteronuclear Single Quantum Correlation - Distortionless Enhancement by Polarization Transfer (HSQC-DEPT) NMR spectra obtained in $\mathrm{C}_{6} \mathrm{D}_{6}$ for NMI treated with $\mathrm{NaBH}_{4}$ after anion exchange with TBACl. The $y$ axis ( $f 1$ ) corresponds to the ${ }^{13} \mathrm{C}$ chemical shift of the carbon with attached protons at the ${ }^{1} \mathrm{H}$ chemical shift indicated in the $\mathrm{x}$-axis (f2). The phase is represented by color: blue colors indicate $\mathrm{CH}_{2}$ groups whereas red colors indicate $\mathrm{CH}$ or $\mathrm{CH}_{3}$ groups. Tentative peak assignments via density functional theory calculations are provided in section $\mathrm{G}$. of this supporting information. 


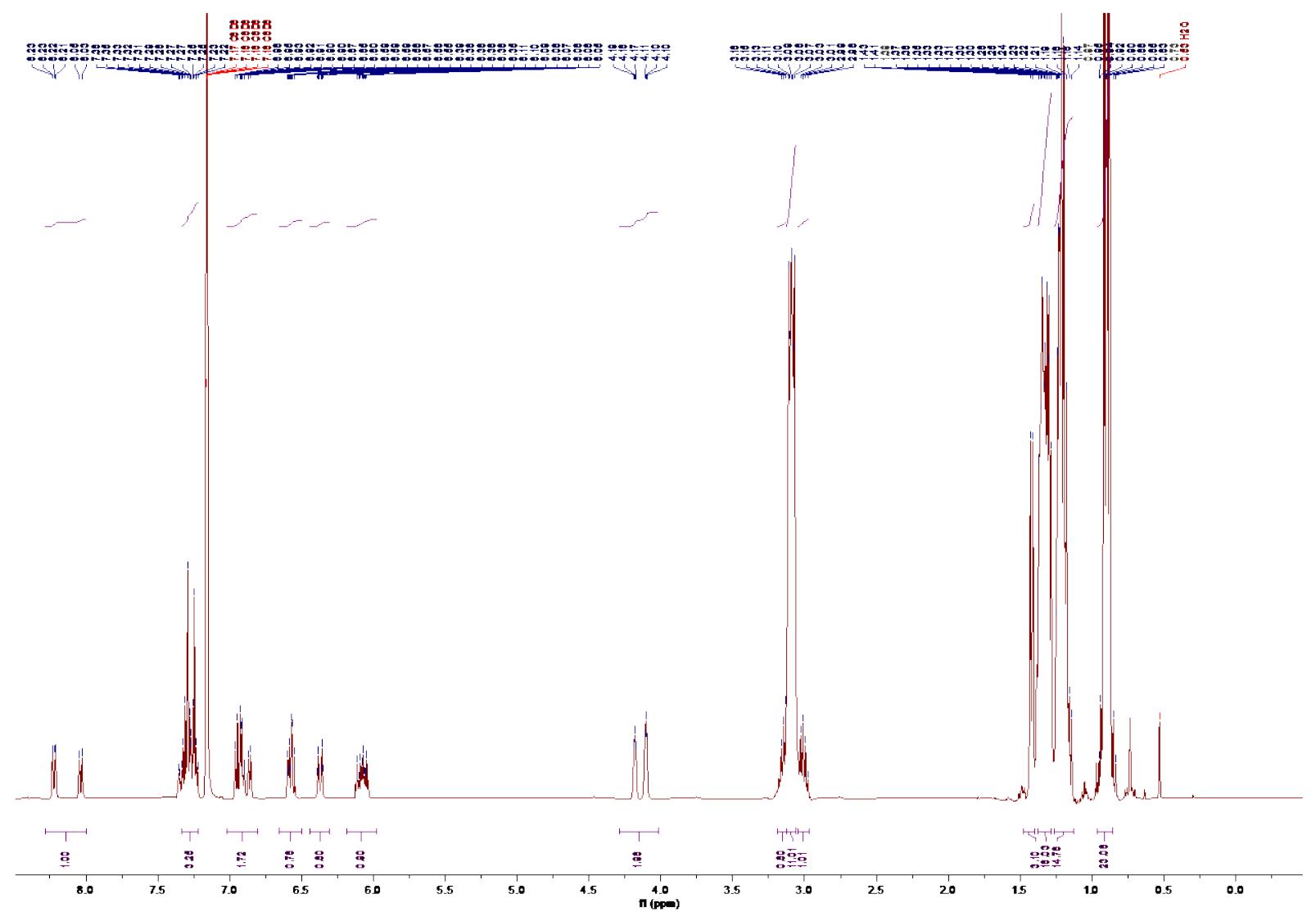

Figure S12. ${ }^{1} \mathrm{H}$ NMR spectrum obtained in $\mathrm{C}_{6} \mathrm{D}_{6}$ for $\mathrm{NMI}$ treated with $\mathrm{NaBH}_{4}$ after anion exchange with TBACl. ${ }^{1} \mathrm{H} \mathrm{NMR}\left(400 \mathrm{MHz}, \mathrm{C}_{6} \mathrm{D}_{6}\right) \delta 8.28-8.00(\mathrm{~m}, 1 \mathrm{H}), 7.34-7.22(\mathrm{~m}, 3 \mathrm{H}), 7.02-6.81(\mathrm{~m}, 2 \mathrm{H}), 6.66-6.50(\mathrm{~m}, 1 \mathrm{H})$, $6.37(\mathrm{dt}, \mathrm{J}=9.9,2.2 \mathrm{~Hz}, 1 \mathrm{H}), 6.19-5.98(\mathrm{~m}, 1 \mathrm{H}), 4.14(\mathrm{~m}, 2 \mathrm{H}), 3.15(\mathrm{q}, \mathrm{J}=6.9 \mathrm{~Hz}, 1 \mathrm{H}), 3.13-3.06(\mathrm{~m}, 11 \mathrm{H})$, $3.01(p, J=6.8 \mathrm{~Hz}, 1 \mathrm{H}), 1.42(\mathrm{~d}, \mathrm{~J}=6.8 \mathrm{~Hz}, 3 \mathrm{H}), 1.37-1.28(\mathrm{~m}, 18 \mathrm{H}), 1.22(\mathrm{dd}, \mathrm{J}=9.5,5.1 \mathrm{~Hz}, 15 \mathrm{H}), 0.90(\mathrm{t}$, $J=7.3 \mathrm{~Hz}, 23 \mathrm{H})$. 


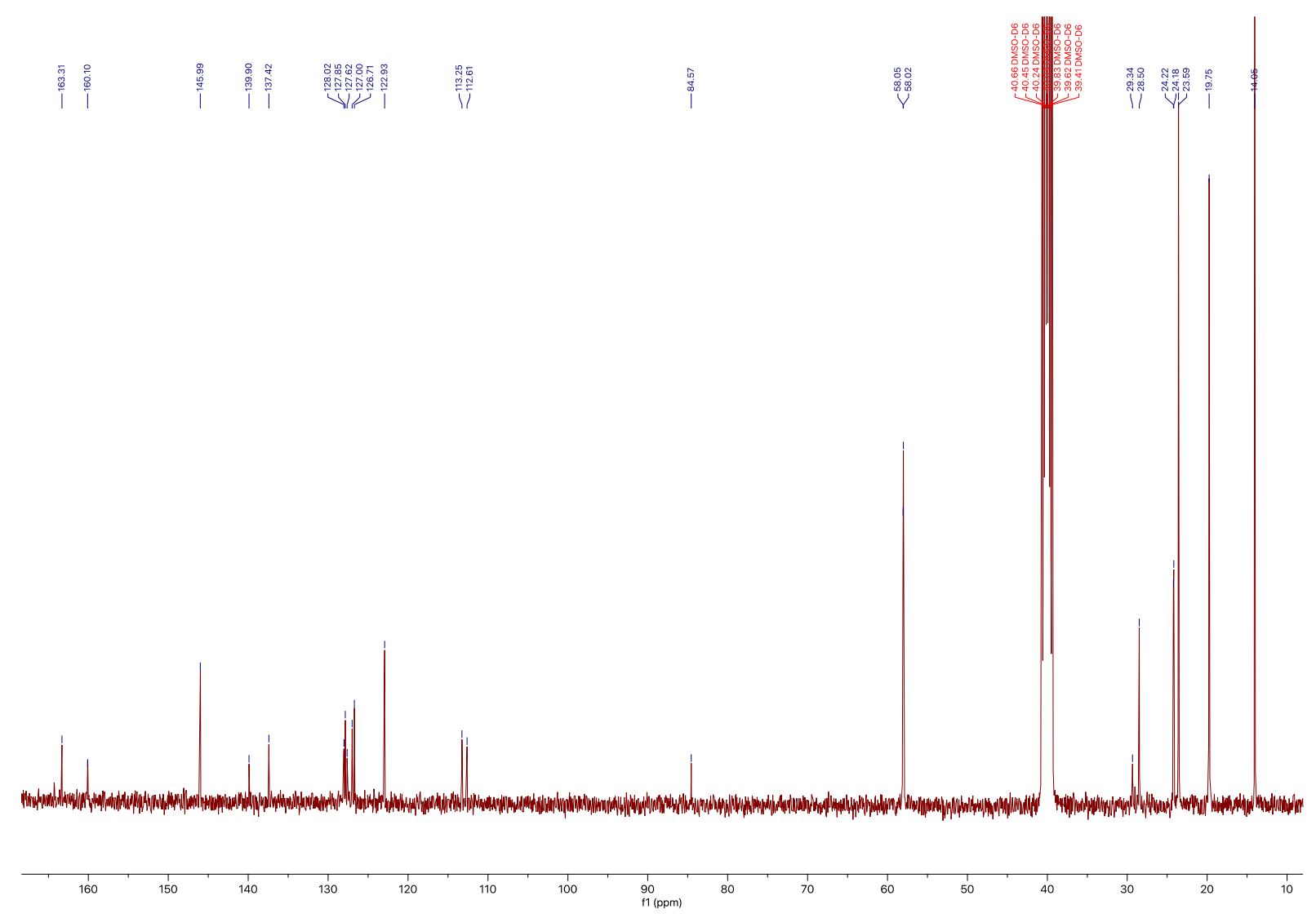

Figure S13. ${ }^{13} \mathrm{C}$ NMR spectrum obtained in DMSO-D6 for $\mathrm{NMI}$ treated with $\mathrm{NaBH}_{4}$ after anion exchange with TBACl . ${ }^{13} \mathrm{C}$ NMR (101 MHz, DMSO-D 6 ) $\delta$ 163.31, 160.10, 145.99, 139.90, 137.42, 128.02, 127.85, 127.62, $127.00,126.71,122.93,113.25,112.61,84.57,58.02,29.34,28.50,24.22,24.18,23.59,19.75,14.05$. 

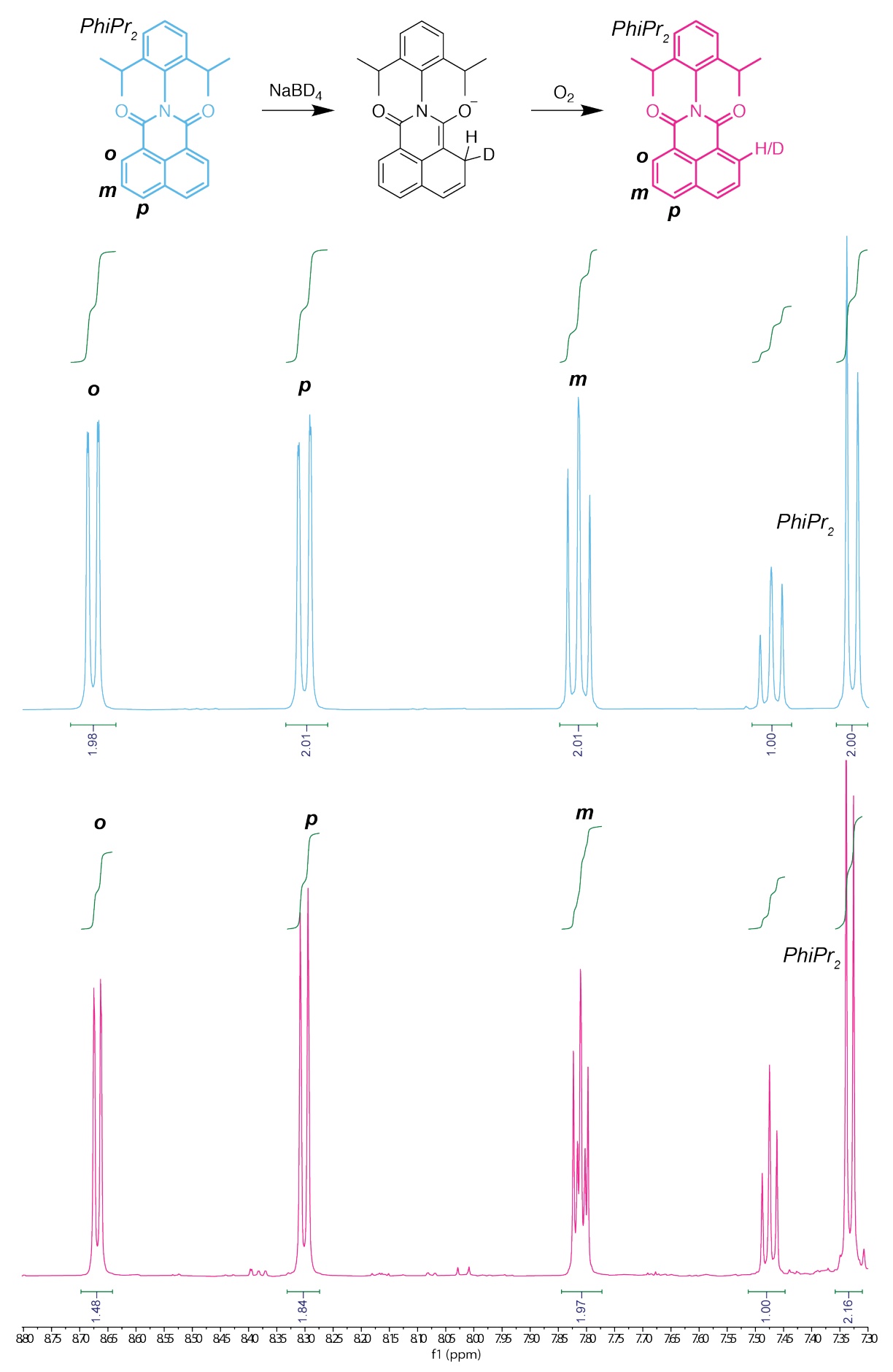

Figure S14. ${ }^{1} \mathrm{H}$ NMR of starting material NMI (top, blue) and NMI after treatment with 1 eq. $\mathrm{NaBD}_{4}$, followed by oxidation in air (bottom, pink). A notable decrease in the ortho- (o) integrated area is evident following deuteration, as well as extra J coupling on the meta- $(\mathrm{m})$ position. Top spectrum (blue, NMI): ${ }^{1} \mathrm{H}$ NMR (400 $\left.\mathrm{MHz}, \mathrm{CDCl}_{3}\right) \delta 8.67(\mathrm{dd}, \mathrm{J}=7.3,1.1 \mathrm{~Hz}, 2 \mathrm{H}), 8.30(\mathrm{dd}, \mathrm{J}=8.2,1.2 \mathrm{~Hz}, 2 \mathrm{H}), 7.81(\mathrm{dd}, \mathrm{J}=8.3,7.3 \mathrm{~Hz}, 2 \mathrm{H}), 7.51$ $-7.44(\mathrm{t}, \mathrm{J}=7.7 \mathrm{~Hz}, 1 \mathrm{H}), 7.33(\mathrm{~d}, \mathrm{~J}=7.7 \mathrm{~Hz}, 2 \mathrm{H})$. Bottom spectrum (pink, NMI(H/D): ${ }^{1} \mathrm{H}$ NMR $(600 \mathrm{MHz}$, $\left.\mathrm{CDCl}_{3}\right) \delta 8.67(\mathrm{dd}, \mathrm{J}=7.2,1.2 \mathrm{~Hz}, 1.48 \mathrm{H}), 8.30(\mathrm{dd}, \mathrm{J}=8.2,1.2 \mathrm{~Hz}, 1.84 \mathrm{H}), 7.84-7.77(\mathrm{~m}, \mathrm{~J}=7.5,4.0 \mathrm{~Hz}, 2 \mathrm{H})$, $7.47(\mathrm{t}, \mathrm{J}=7.8 \mathrm{~Hz}, 1 \mathrm{H}), 7.33(\mathrm{~d}, \mathrm{~J}=7.8 \mathrm{~Hz}, 2 \mathrm{H})$. 


\section{E. Single-Crystal X-ray Diffraction}

X-ray diffraction analysis was performed on single crystals coated with Paratone-N oil and mounted on a glass fiber for $[\mathrm{NMI}(\mathrm{H})]^{-}[\mathrm{TBA}]^{+}$and a MiTeGen loop for NMI. Crystals were frozen at $100 \mathrm{~K}$ by Oxford Cryosystems Cryostreams during the experiments. Data for $[\mathrm{NMI}(\mathrm{H})]^{-}[\mathrm{TBA}]^{+}$were collected at ChemMatCARS at the Advanced Photon Source at Argonne National Laboratory using synchrotron radiation $(\lambda=0.41328 \AA$ ) on a Huber three-circle diffractometer equipped with a Pilatus $1 \mathrm{M}(\mathrm{CdTe})$ detector, while data for the neutral NMI were collected at the Harvard Department of Chemistry and Chemical Biology X-ray Laboratory on a Bruker D8 Venture diffractometer equipped with a Bruker PHOTON100 CMOS detector. Raw data were integrated and corrected for Lorentz and polarization effects using Bruker AXS SAINT software. ${ }^{3}$ Absorption corrections were applied using SADABS. ${ }^{4}$ Space group assignments were determined by examination of systematic absences, E-statistics, and successive refinement of the structures. Both structures were solved by intrinsic phasing using SHELXT. ${ }^{5}$ All structures were refined using SHELXL ${ }^{6}$ operated in the OLEX $2^{7}$ interface. No significant crystal decay was observed during data collection.

During initial refinement of the structure of $[\mathrm{NMI}(\mathrm{H})]^{-}[\mathrm{TBA}]^{+}$, the two carbon atoms on the 2- and 7-positions of the reduced naphthalene ring were found to have longer $\mathrm{C}-\mathrm{C}$ bond distances than those expected for $\mathrm{sp}^{2}$ hybridized carbon atoms. Residual electron density close to these carbon atoms suggested the presence of both $\mathrm{C}\left(\mathrm{sp}^{3}\right) \mathrm{H}_{2}$ and $\mathrm{C}\left(\mathrm{sp}^{2}\right) \mathrm{H}$ hydrogen atoms. Based on these observations and characterization by NMR spectroscopy, the structure was assigned as a twoelectron reduced Meisenheimer complex with one $\mathrm{sp}^{3}$ hybridized carbon atom and one $\mathrm{sp}^{2}$ hybridized carbon atom disordered over two positions. The final refinement gave a value for $R_{1}$ that was $0.13 \%$ lower compared to a model that did not account for the disorder and $0.15 \%$ lower compared to a model that assigned the two carbon atoms as $\mathrm{C}\left(\mathrm{sp}^{2}\right) \mathrm{H}$ groups.

Thermal parameters for both structures were refined anisotropically for all non-hydrogen atoms. For the structure of $[\mathrm{NMI}(\mathrm{H})]^{-}[\mathrm{TBA}]^{+}$, disorder of the carbon atoms on the reduced naphthalene ring required displacement parameter restraints (SIMU and RIGU), while disorder of two carbon atoms of the tetrabutylammonium counteraction required both displacement parameter restraints (SIMU and RIGU) and distance restraints (DFIX). Hydrogen atoms in both structures were placed in ideal positions and refined using a riding model for all structures. 

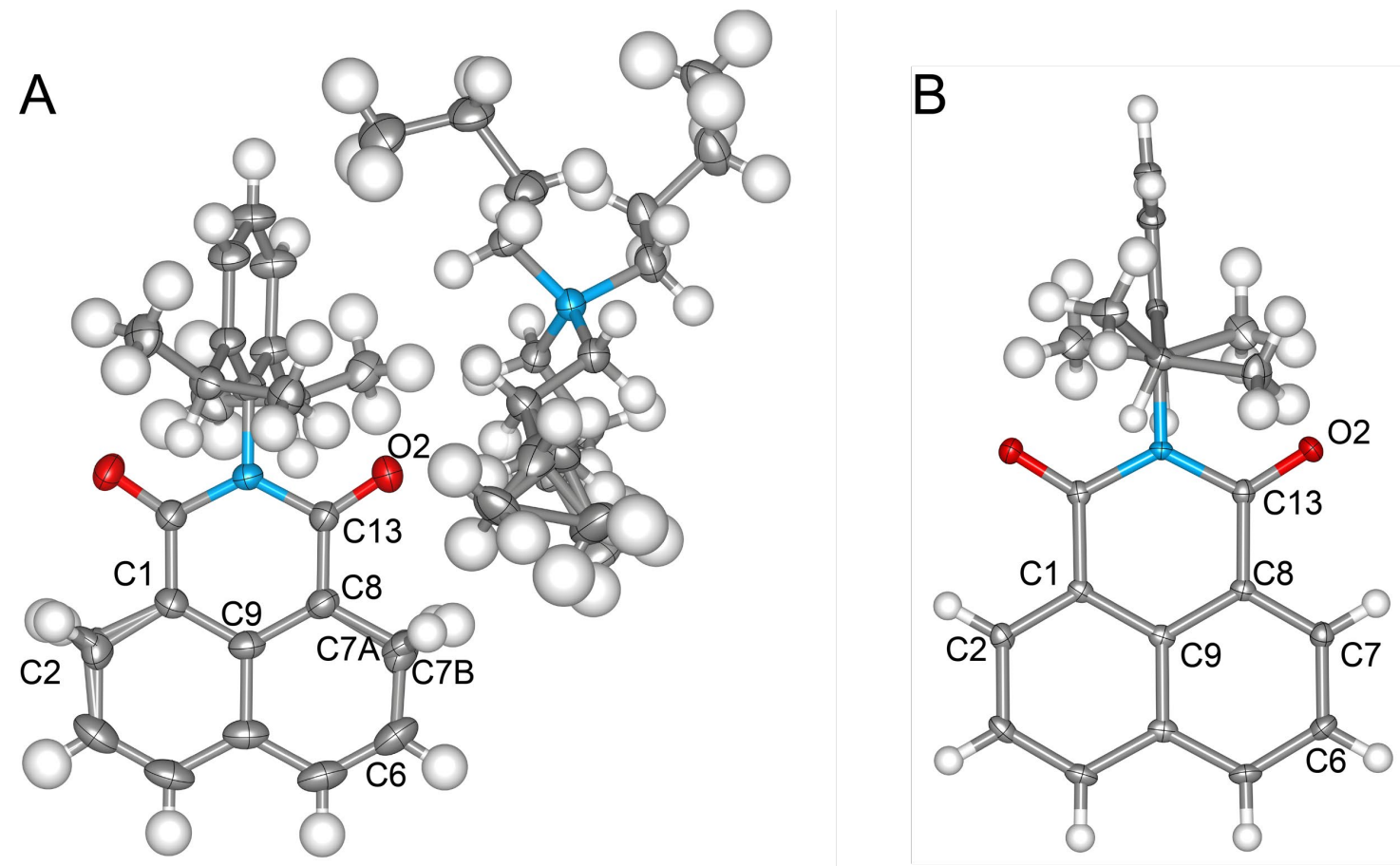

Figure S15. (A) Atomic displacement parameter plot for the solid-state structure of $[\mathrm{NMI}(\mathrm{H})]^{-}[\mathrm{TBA}]^{+}$at 100 $\mathrm{K}$ drawn at $50 \%$ probability level as determined by single-crystal $\mathrm{X}$-ray diffraction. The carbon atoms at the 2- and 7-positions of the reduced naphthalene ring correspond to one $\mathrm{sp}^{2}$ hybridized carbon atom and one $\mathrm{sp}^{3}$ hybridized carbon atom disorder over the two positions (relative occupancy of 42(3):58(3)). Two carbon atoms on the TBA countercation are also disordered over two positions (relative occupancy of 83.8(9):16.2(9)). (B) Atomic displacement parameter plot for the solid-state structure of $\mathrm{NMI}$ at $100 \mathrm{~K}$ drawn at 50\% probability level as determined by single-crystal X-ray diffraction. Red, blue, gray, and white ellipsoids represent $\mathrm{O}, \mathrm{N}, \mathrm{C}$, and $\mathrm{H}$ atoms, respectively.

Table S1. Selected bond lengths and angles for [NMI(H)]-

\begin{tabular}{lcl}
\hline Compound & {$[\mathrm{NMI}(\mathrm{H})]^{-}[\mathrm{TBA}]^{+}$} & \multicolumn{1}{c}{$\mathrm{NMI}$} \\
\hline $\mathrm{C} 9-\mathrm{C} 8$ & $1.411(3) \AA$ & $1.4182(19) \AA$ \\
$\mathrm{C} 8-\mathrm{C7}(\mathrm{A})\left(58 \%\right.$ occ. $\left.[\mathrm{NMI}(\mathrm{H})]^{-}\right)$ & $1.456(15) \AA$ & $1.374(3) \AA$ \\
C8-C7B $\left(42 \%\right.$ occ. $\left.[\mathrm{NMI}(\mathrm{H})]^{-}\right)$ & $1.51(3) \AA$ & - \\
$\mathrm{C} 7(\mathrm{~A})-\mathrm{C} 6$ & $1.484(15) \AA$ & $1.402(3) \AA$ \\
$\mathrm{C} 7 \mathrm{~B}-\mathrm{C6}$ & $1.38(3) \AA$ & - \\
$\mathrm{C} 8-\mathrm{C} 13$ & $1.428(3) \AA$ & $1.479(2) \AA$ \\
$\mathrm{C} 13-\mathrm{O} 2$ & $1.253(2) \AA$ & $1.2158(18) \AA$ \\
Omega(C13-C8-C9-C1) & $2.5(3)^{\circ}$ & $0.37(2)^{\circ}$ \\
\hline
\end{tabular}


Table S2. Crystallographic data for [NMI(H)]-

\begin{tabular}{|c|c|c|}
\hline Compound & {$[\mathrm{NMI}(\mathrm{H})]^{-}[\mathrm{TBA}]^{+}$} & $\mathrm{NMI}$ \\
\hline Formula & $\mathrm{C}_{40} \mathrm{H}_{60} \mathrm{~N}_{2} \mathrm{O}_{2}$ & $\mathrm{C}_{24} \mathrm{H}_{23} \mathrm{NO}_{2}$ \\
\hline$T(K)$ & $100(2)$ & $100(2)$ \\
\hline Crystal System & Monoclinic & Monoclinic \\
\hline Space Group & $\mathrm{Cc}$ & $C 2 / c$ \\
\hline$a(\AA)$ & $17.7475(13)$ & $14.4054(12)$ \\
\hline$b(\AA)$ & $11.9924(9)$ & $9.3527(8)$ \\
\hline$c(\AA)$ & $17.5891(12)$ & $27.510(2)$ \\
\hline$\alpha\left(^{\circ}\right)$ & 90 & 90 \\
\hline$B\left(1^{\circ}\right)$ & $96.0850(15)$ & $97.815(3)$ \\
\hline$\gamma\left(\left(^{\circ}\right)\right.$ & 90 & 90 \\
\hline$V\left(\AA^{3}\right)$ & $3722.5(5)$ & $3672.0(5)$ \\
\hline Z & 4 & 8 \\
\hline Radiation & Synchrotron & Mo Ka \\
\hline$\lambda(\AA)$ & 0.41328 & 0.71073 \\
\hline $2 \Theta$ Range for Data Collection $\left({ }^{\circ}\right)$ & 2.388 to 35.51 & 5.208 to 51.422 \\
\hline Completeness to $2 \theta$ & $98.4 \%\left(2 \Theta=28.714^{\circ}\right)$ & $95.2 \%\left(2 \Theta=50.484^{\circ}\right)$ \\
\hline Data / Restraints / Parameters & $11716 / 135 / 444$ & $3335 / 0 / 248$ \\
\hline Goodness of Fit on $F^{2}$ & 1.052 & 1.074 \\
\hline $\mathrm{R}_{1}^{\mathrm{a}}$ & 0.0455 & 0.0395 \\
\hline$w R_{2}^{b}(1>2 \sigma(I))$ & 0.1272 & 0.0871 \\
\hline$R_{1}^{a}$ (all data) & 0.0522 & 0.0544 \\
\hline$w R_{2}^{b}$ (all data) & 0.1304 & 0.0940 \\
\hline Largest Diff. Peak and Hole (e $\AA^{-3}$ ) & 0.334 and -0.152 & 0.172 and -0.214 \\
\hline
\end{tabular}

${ }^{a} R_{1}=\Sigma|| F_{0}|-| F_{\mathrm{c}}|| / \Sigma\left|F_{\mathrm{o}}\right| \cdot{ }^{b} w R_{2}=\left\{\Sigma\left[w\left(F_{\mathrm{o}}^{2}-F_{\mathrm{c}}{ }^{2}\right)^{2}\right] / \Sigma\left[w\left(F_{\mathrm{o}}^{2}\right)^{2}\right]\right\}^{1 / 2}$. 


\section{F. Calculated Structures of NMI and $[\mathrm{NMI}(\mathrm{H})]^{-}$}

\section{F.1. Ab initio Computational Methodology}

Geometry optimizations were performed using the program Gaussian $09^{8}$ at the B3LYP/6$311 G+(d, p)^{9-13}$ level of theory with model benzene solvation using the Polarizable Continuum Model (PCM) with the integral equation formalism variant (IEFPCM). Frequency calculations were performed to ensure all structures were at global minima. Four possible isomers of [NMI(H)]- were considered as possible species to correspond to the ${ }^{1} \mathrm{H}$ and ${ }^{13} \mathrm{C}$ NMR signals observed as a result of the reaction of NMI with a hydride source: hydride addition to the naphthalene ring producing either an ortho (ortho- $\left.[\mathrm{NMI}(\mathrm{H})]^{-}\right)$, meta $\left(\right.$meta- $\left.[\mathrm{NMI}(\mathrm{H})]^{-}\right)$or a para isomer (para- $\left.[\mathrm{NMI}(\mathrm{H})]^{-}\right)$, or to a carboxamide carbon (carbo-[NMI $\left.(\mathrm{H})]^{-}\right)$. The coordinates of the optimized structures of these species are deposited in the appendix of this supplementary material and were then used to perform an NMR calculation with the program Gaussian 09 using the GIAO method ${ }^{14-18}$ with the same level of theory and implicit solvent as for the geometry optimizations. These calculations were performed using Gaussian 09 with the following keywords: nmr=giao b3lyp/6-311+g(d,p) scrf=(iefpcm,solvent=benzene). A plot of the experimental vs. calculated absolute chemical shielding was constructed using the parent NMI as a calibration standard. 
F.2. NMI

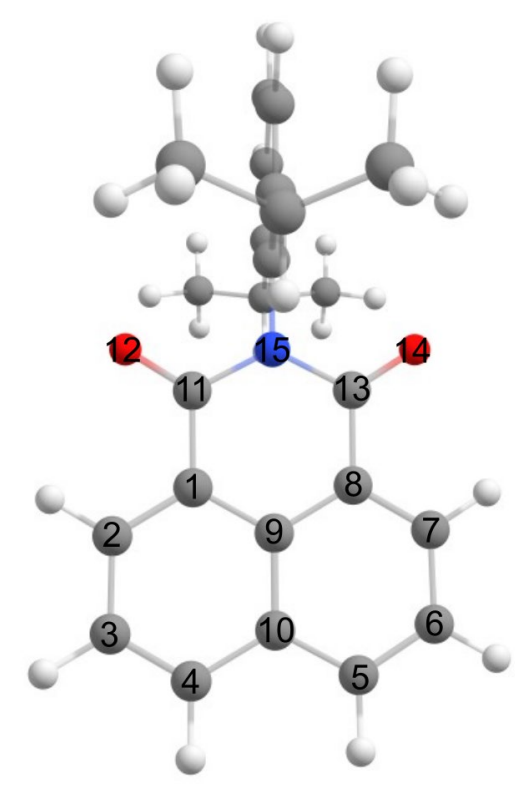

Figure S16. Calculated structure of $\mathrm{NMI}$ at the at the $\mathrm{B} 3 \mathrm{LYP} / 6-311 \mathrm{G}+(\mathrm{d}, \mathrm{p})$ level of theory. Selected interatomic distances $(\AA ̊)$ : C1-C2 1.383, C2-C3 1.408, C3-C4 1.378, C4-C10 1.418, C9-C10 1.427, C9C1 1.416, C1-C11 1.483, C11-012 1.218.

Table S3. NMI xyz coordinates optimized at the B3LYP/6-311G+(d,p) level of theory used for GIAO NMR calculations.

\begin{tabular}{|l|r|r|r|}
\hline Atom & $x$ & $y$ & $z$ \\
\cline { 1 - 1 } C7 & -2.56240000 & -0.09370000 & 2.42400000 \\
\cline { 1 - 1 } C8 & -1.86560000 & -0.04780000 & 1.23060000 \\
\hline C9 & -2.56520000 & -0.00010000 & 0.00000000 \\
\hline C10 & -3.99210000 & -0.00010000 & 0.00000000 \\
\hline C5 & -4.67180000 & -0.04820000 & 1.24370000 \\
\hline H7 & -3.97080000 & -0.09390000 & 2.42890000 \\
\hline C1 & -2.00640000 & -0.12940000 & 3.35250000 \\
\hline C4 & -1.86560000 & 0.04760000 & -1.23070000 \\
\hline H5 & -4.67180000 & 0.04810000 & -1.24380000 \\
\hline H6 & -5.75650000 & -0.04850000 & 1.24860000 \\
\hline C3 & -4.50070000 & -0.13030000 & 3.37320000 \\
\hline H4 & -3.97080000 & 0.09380000 & -2.42900000 \\
\hline H3 & -2.56240000 & 0.09350000 & -2.42400000 \\
\hline
\end{tabular}




\begin{tabular}{|c|c|c|c|}
\hline $\mathrm{H} 2$ & -2.00640000 & 0.12920000 & -3.35260000 \\
\hline C13 & -0.38300000 & -0.04850000 & 1.24920000 \\
\hline C11 & -0.38300000 & 0.04830000 & -1.24930000 \\
\hline 014 & 0.26390000 & -0.08870000 & 2.28040000 \\
\hline 012 & 0.26390000 & 0.08830000 & -2.28050000 \\
\hline N15 & 0.26590000 & -0.00010000 & 0.00000000 \\
\hline C16 & 1.72140000 & 0.00000000 & 0.00000000 \\
\hline C17 & 2.39700000 & 1.23080000 & 0.03440000 \\
\hline C18 & 2.39720000 & -1.23050000 & -0.03440000 \\
\hline C19 & 3.79470000 & 1.20350000 & 0.03360000 \\
\hline $\mathrm{C} 20$ & 3.79490000 & -1.20300000 & -0.03380000 \\
\hline C21 & 4.48920000 & 0.00030000 & -0.00020000 \\
\hline $\mathrm{H} 19$ & 4.34670000 & 2.13620000 & 0.05920000 \\
\hline $\mathrm{H} 2 \mathrm{O}$ & 4.34710000 & -2.13560000 & -0.05950000 \\
\hline $\mathrm{H} 21$ & 5.57380000 & 0.00040000 & -0.00030000 \\
\hline $\mathrm{C} 22$ & 1.67000000 & -2.56960000 & -0.06830000 \\
\hline $\mathrm{H} 22$ & 0.59610000 & -2.37270000 & -0.07380000 \\
\hline C23 & 1.66960000 & 2.56970000 & 0.06840000 \\
\hline $\mathrm{H} 23$ & 0.59570000 & 2.37270000 & 0.07370000 \\
\hline C24 & 1.98980000 & -3.35750000 & -1.35260000 \\
\hline $\mathrm{H} 24 \mathrm{a}$ & 1.75210000 & -2.77180000 & -2.24360000 \\
\hline $\mathrm{H} 24 \mathrm{~b}$ & 3.04790000 & -3.63090000 & -1.40070000 \\
\hline $\mathrm{H} 24 \mathrm{c}$ & 1.40620000 & -4.28250000 & -1.38400000 \\
\hline $\mathrm{C} 25$ & 1.96900000 & -3.40650000 & 1.19000000 \\
\hline $\mathrm{H} 25 \mathrm{a}$ & 1.71600000 & -2.85480000 & 2.09830000 \\
\hline $\mathrm{H} 25 \mathrm{~b}$ & 1.38620000 & -4.33240000 & 1.17660000 \\
\hline $\mathrm{H} 25 \mathrm{c}$ & 3.02670000 & -3.68020000 & 1.24460000 \\
\hline C26 & 1.96870000 & 3.40690000 & -1.18960000 \\
\hline $\mathrm{H} 26 \mathrm{a}$ & 3.02630000 & 3.68090000 & -1.24390000 \\
\hline $\mathrm{H} 26 \mathrm{~b}$ & 1.71600000 & 2.85550000 & -2.09810000 \\
\hline $\mathrm{H} 26 \mathrm{c}$ & 1.38560000 & 4.33280000 & -1.17610000 \\
\hline $\mathrm{C} 27$ & 1.98900000 & 3.35730000 & 1.35300000 \\
\hline $\mathrm{H} 27 \mathrm{a}$ & 1.40540000 & 4.28230000 & 1.38450000 \\
\hline $\mathrm{H} 27 \mathrm{~b}$ & 1.75100000 & 2.77140000 & 2.24380000 \\
\hline $\mathrm{H} 27 \mathrm{c}$ & 3.04700000 & 3.63070000 & 1.40150000 \\
\hline
\end{tabular}




\section{F.3. ortho- $[\mathrm{NMI}(\mathrm{H})]^{-}$}

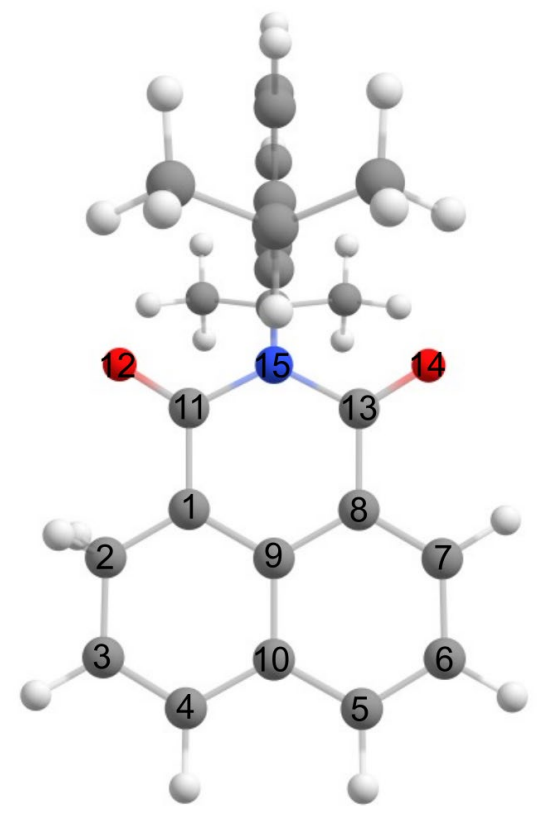

Figure S17. Calculated structure of ortho-[NMI $(\mathrm{H})]^{-}$at the at the B3LYP/6-311G+(d,p) level of theory. Selected interatomic distances ( $\AA$ ): C1-C2 1.514, C2-C3 1.503, C3-C4 1.342, C4-C10 1.458, C10-C5 1.384, C5-C6 1.411, C6-C7 1.383, C7-C8 1.407, C8-C9 1.427, C9-C10 1.443, C9-C1 1.405, C1-C11 1.412, C11-012 1.249, C13-014 1.241.

Table S4. Coordinates of ortho-[NMI(H)] $]^{-}$optimized at the B3LYP/6-311G+(d,p) level of theory used for GIAO NMR calculations.

\begin{tabular}{|l|c|c|c|}
\hline Atom & $\mathbf{x}$ & $\mathbf{y}$ & $\mathbf{z}$ \\
\hline C7 & -2.51930000 & -0.06000000 & 2.49980000 \\
\hline C8 & -1.80970000 & -0.03110000 & 1.28460000 \\
\hline C9 & -2.50370000 & -0.00570000 & 0.03740000 \\
\hline C10 & -3.94570000 & -0.00260000 & 0.07890000 \\
\hline C5 & -4.60480000 & -0.03070000 & 1.29550000 \\
\hline C6 & -3.90200000 & -0.06190000 & 2.51870000 \\
\hline H7 & -1.94530000 & -0.07900000 & 3.41930000 \\
\hline C1 & -1.81660000 & 0.01980000 & -1.18730000 \\
\hline C4 & -4.66200000 & 0.03810000 & -1.190500000 \\
\hline H6 & -5.69210000 & -0.02710000 & 1.30130000 \\
\hline C3 & -4.44240000 & -0.08300000 & 3.45860000 \\
\hline C2 & -4.03280000 & 0.06010000 & -2.37520000 \\
\hline
\end{tabular}




\begin{tabular}{|c|c|c|c|}
\hline $\mathrm{H} 4$ & -5.74890000 & 0.05440000 & -1.15190000 \\
\hline H3 & -4.61810000 & 0.09330000 & -3.29110000 \\
\hline $\mathrm{H} 2$ & -2.24220000 & -0.83860000 & -3.12690000 \\
\hline $\mathrm{C} 13$ & -0.35440000 & -0.02680000 & 1.30890000 \\
\hline C11 & -0.40510000 & 0.02440000 & -1.21490000 \\
\hline $\mathrm{O} 14$ & 0.32710000 & -0.04600000 & 2.34610000 \\
\hline 012 & 0.29610000 & 0.04430000 & -2.24880000 \\
\hline N15 & 0.26800000 & 0.00100000 & 0.05610000 \\
\hline C16 & 1.71350000 & 0.00220000 & 0.03080000 \\
\hline C17 & 2.39890000 & 1.22930000 & 0.04350000 \\
\hline $\mathrm{C} 18$ & 2.40030000 & -1.22300000 & -0.01020000 \\
\hline C19 & 3.79660000 & 1.20700000 & 0.01410000 \\
\hline C20 & 3.79810000 & -1.19780000 & -0.03600000 \\
\hline $\mathrm{C} 21$ & 4.49450000 & 0.00520000 & -0.02390000 \\
\hline H19 & 4.34690000 & 2.14210000 & 0.01690000 \\
\hline $\mathrm{H} 2 \mathrm{O}$ & 4.34920000 & -2.13190000 & -0.06730000 \\
\hline $\mathrm{H} 21$ & 5.57980000 & 0.00620000 & -0.04470000 \\
\hline $\mathrm{C} 22$ & 1.66810000 & -2.55870000 & -0.04290000 \\
\hline $\mathrm{H} 22$ & 0.59840000 & -2.34960000 & -0.00560000 \\
\hline C23 & 1.66160000 & 2.56260000 & 0.05820000 \\
\hline $\mathrm{H} 23$ & 0.59930000 & 2.34950000 & 0.18480000 \\
\hline C24 & 1.93720000 & -3.31450000 & -1.35780000 \\
\hline $\mathrm{H} 24 \mathrm{a}$ & 1.66940000 & -2.69810000 & -2.21900000 \\
\hline $\mathrm{H} 24 \mathrm{~b}$ & 2.99230000 & -3.59240000 & -1.45130000 \\
\hline $\mathrm{H} 24 \mathrm{c}$ & 1.34520000 & -4.23500000 & -1.39590000 \\
\hline $\mathrm{C} 25$ & 2.00460000 & -3.42640000 & 1.18380000 \\
\hline $\mathrm{H} 25 \mathrm{a}$ & 1.77340000 & -2.89540000 & 2.11000000 \\
\hline $\mathrm{H} 25 \mathrm{~b}$ & 1.42110000 & -4.35280000 & 1.16610000 \\
\hline $\mathrm{H} 25 \mathrm{c}$ & 3.06430000 & -3.70100000 & 1.20360000 \\
\hline $\mathrm{C} 26$ & 1.81860000 & 3.29820000 & -1.28600000 \\
\hline $\mathrm{H} 26 \mathrm{a}$ & 2.86400000 & 3.56520000 & -1.47350000 \\
\hline $\mathrm{H} 26 \mathrm{~b}$ & 1.47280000 & 2.66770000 & -2.10790000 \\
\hline $\mathrm{H} 26 \mathrm{c}$ & 1.23060000 & 4.22220000 & -1.28660000 \\
\hline $\mathrm{C} 27$ & 2.09080000 & 3.45120000 & 1.23950000 \\
\hline $\mathrm{H} 27 \mathrm{a}$ & 1.48710000 & 4.36410000 & 1.26500000 \\
\hline $\mathrm{H} 27 \mathrm{~b}$ & 1.95780000 & 2.92760000 & 2.18910000 \\
\hline $\mathrm{H} 27 \mathrm{c}$ & 3.14060000 & 3.75130000 & 1.16050000 \\
\hline $\mathrm{H} 2 \mathrm{~b}$ & -2.20710000 & 0.89110000 & -3.12750000 \\
\hline
\end{tabular}




\section{F.4. para-[NMI(H)]-}

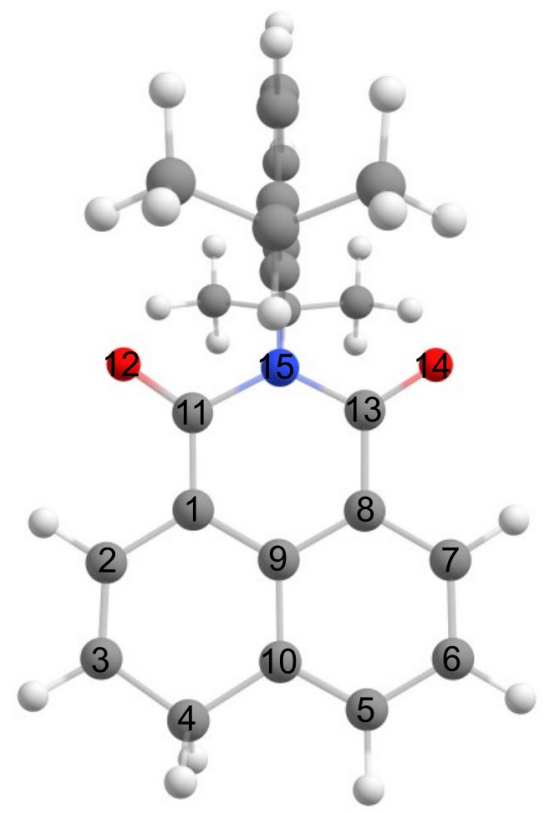

Figure S18. Calculated structure of para- $[\mathrm{NMI}(\mathrm{H})]^{-}$at the at the $\mathrm{B} 3 \mathrm{LYP} / 6-311 \mathrm{G}+(\mathrm{d}, \mathrm{p})$ level of theory. Selected interatomic distances (Å): C1-C2 1.450, C2-C3 1.345, C3-C4 1.508, C4-C10 1.524, C10-C5 1.384, C5-C6 1.409, C6-C7 1.381, C7-C8 1.407, C8-C9 1.420, C9-C10 1.431, C9-C1 1.426, C1-C11 1.412, C11-O12 1.254, C13-014 1.242.

Table S5. Coordinates of para-[NMI(H)]- optimized at the B3LYP/6-311G+(d,p) level of theory used for GIAO NMR calculations.

\begin{tabular}{|l|c|c|r|}
\hline Atom & $\mathbf{x}$ & $\mathrm{y}$ & $\mathbf{z}$ \\
\hline C7 & -2.58280000 & 0.00170000 & -2.44500000 \\
\hline C8 & -1.81450000 & 0.00090000 & -1.21480000 \\
\hline C9 & -2.51160000 & 0.00010000 & 0.02880000 \\
\hline C10 & -3.94210000 & 0.00000000 & 0.06970000 \\
\hline C5 & -4.76200000 & 0.00130000 & -1.21500000 \\
\hline C6 & -3.92760000 & 0.00180000 & -2.47100000 \\
\hline H7 & -2.02310000 & 0.00210000 & -3.37440000 \\
\hline C1 & -1.80230000 & -0.00090000 & 1.25900000 \\
\hline H5 & -4.58240000 & -0.00100000 & 1.29680000 \\
\hline H6 & -5.43620000 & 0.87050000 & -1.21520000 \\
\hline C3 & -4.45720000 & 0.00230000 & -3.41890000 \\
\hline C2 & -3.87050000 & -0.00200000 & 2.51280000 \\
\hline H4 & -2.48940000 & -0.00190000 & 2.48680000 \\
\hline
\end{tabular}




\begin{tabular}{|c|c|c|c|}
\hline H3 & -4.40580000 & -0.00290000 & 3.45550000 \\
\hline $\mathrm{H} 2$ & -1.91220000 & -0.00270000 & 3.40320000 \\
\hline $\mathrm{C} 13$ & -0.40330000 & 0.00090000 & -1.25800000 \\
\hline C11 & -0.34050000 & -0.00080000 & 1.25960000 \\
\hline O14 & 0.30580000 & 0.00160000 & -2.29200000 \\
\hline 012 & 0.34010000 & -0.00150000 & 2.29910000 \\
\hline N15 & 0.27690000 & 0.00000000 & 0.01210000 \\
\hline C16 & 1.72550000 & 0.00000000 & -0.01240000 \\
\hline C17 & 2.41000000 & -1.22910000 & -0.02220000 \\
\hline $\mathrm{C} 18$ & 2.41000000 & 1.22910000 & -0.02090000 \\
\hline C19 & 3.80890000 & -1.20370000 & -0.04170000 \\
\hline $\mathrm{C} 20$ & 3.80900000 & 1.20370000 & -0.04030000 \\
\hline $\mathrm{C} 21$ & 4.50590000 & 0.00000000 & -0.05100000 \\
\hline H19 & 4.36090000 & -2.13720000 & -0.04920000 \\
\hline $\mathrm{H} 2 \mathrm{O}$ & 4.36100000 & 2.13710000 & -0.04680000 \\
\hline $\mathrm{H} 21$ & 5.59060000 & -0.00010000 & -0.06610000 \\
\hline $\mathrm{C} 22$ & 1.68260000 & 2.56920000 & -0.00460000 \\
\hline $\mathrm{H} 22$ & 0.61040000 & 2.36680000 & -0.01550000 \\
\hline $\mathrm{C} 23$ & 1.68250000 & -2.56920000 & -0.00730000 \\
\hline $\mathrm{H} 23$ & 0.61030000 & -2.36670000 & -0.01840000 \\
\hline $\mathrm{C} 24$ & 1.98650000 & 3.36380000 & 1.28020000 \\
\hline $\mathrm{H} 24 \mathrm{a}$ & 1.73350000 & 2.78460000 & 2.17130000 \\
\hline $\mathrm{H} 24 \mathrm{~b}$ & 3.04510000 & 3.63440000 & 1.34040000 \\
\hline $\mathrm{H} 24 \mathrm{c}$ & 1.40470000 & 4.29040000 & 1.29920000 \\
\hline $\mathrm{C} 25$ & 2.00030000 & 3.41080000 & -1.25520000 \\
\hline $\mathrm{H} 25 \mathrm{a}$ & 1.75610000 & 2.86640000 & -2.17040000 \\
\hline $\mathrm{H} 25 \mathrm{~b}$ & 1.41770000 & 4.33690000 & -1.24480000 \\
\hline $\mathrm{H} 25 \mathrm{c}$ & 3.05860000 & 3.68530000 & -1.29570000 \\
\hline $\mathrm{C} 26$ & 1.98600000 & -3.36480000 & 1.27700000 \\
\hline $\mathrm{H} 26 \mathrm{a}$ & 3.04450000 & -3.63550000 & 1.33730000 \\
\hline $\mathrm{H} 26 \mathrm{~b}$ & 1.73270000 & -2.78620000 & 2.16850000 \\
\hline $\mathrm{H} 26 \mathrm{c}$ & 1.40410000 & -4.29140000 & 1.29510000 \\
\hline $\mathrm{C} 27$ & 2.00050000 & -3.40980000 & -1.25840000 \\
\hline $\mathrm{H} 27 \mathrm{a}$ & 1.41780000 & -4.33600000 & -1.24880000 \\
\hline $\mathrm{H} 27 \mathrm{~b}$ & 1.75660000 & -2.86480000 & -2.17330000 \\
\hline $\mathrm{H} 27 \mathrm{c}$ & 3.05880000 & -3.68440000 & -1.29890000 \\
\hline $\mathrm{H} 4 \mathrm{~b}$ & -5.43710000 & -0.86720000 & -1.21630000 \\
\hline
\end{tabular}




\section{F.5. meta-[NMI(H)]-}

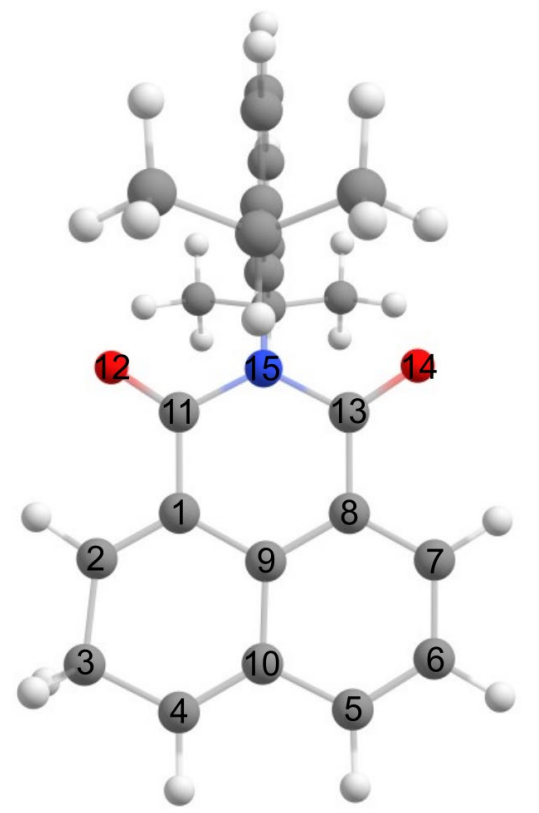

Figure S19. Calculated structure of meta-[NMI(H)] $]^{-}$at the at the B3LYP/6-311G+(d,p) level of theory. Selected interatomic distances $(\AA)$ : C1-C2 1.360, C2-C3 1.504, C3-C4 1.513, C4-C10 1.375, C10-C5 $1.448, C 5-C 61.377, C 6-C 71.409, C 7-C 81.404, C 8-C 91.400, C 9-C 101.459, C 9-C 11.440, C 1-C 11$ 1.482, C11-O12 1.225, C13-014 1.224.

Table S6. Coordinates of meta-[NMI(H)] $]^{-}$optimized at the B3LYP/6-311G+(d,p) level of theory used for GIAO NMR calculations.

\begin{tabular}{|l|c|c|c|}
\hline Atom & $x$ & $y$ & $z$ \\
\hline C7 & 2.52270000 & -0.10620000 & -2.38110000 \\
\hline C8 & 1.85450000 & -0.05250000 & -1.19790000 \\
\hline C9 & 2.53520000 & -0.02040000 & 0.07090000 \\
\hline C10 & 3.99370000 & 0.01300000 & 0.03900000 \\
\hline C5 & 4.68510000 & -0.03390000 & -1.14920000 \\
\hline C6 & 4.01920000 & -0.20320000 & -2.49700000 \\
\hline H7 & 1.93390000 & -0.10400000 & -3.29320000 \\
\hline C4 & 1.83190000 & 0.02520000 & 1.28110000 \\
\hline H5 & 4.62520000 & 0.10750000 & 1.33890000 \\
\hline H6 & 5.77130000 & 0.00650000 & -1.12600000 \\
\hline C3 & 4.37130000 & 0.54490000 & -3.23280000 \\
\hline C2 & 3.89940000 & 0.14320000 & 2.50910000 \\
\hline
\end{tabular}




\begin{tabular}{|c|c|c|c|}
\hline $\mathrm{H} 4$ & 5.71070000 & 0.14610000 & 1.37780000 \\
\hline H3 & 4.43140000 & 0.20650000 & 3.45540000 \\
\hline $\mathrm{H} 2$ & 1.92100000 & 0.12160000 & 3.43680000 \\
\hline C13 & 0.37320000 & -0.01300000 & -1.23850000 \\
\hline $\mathrm{C} 11$ & 0.35910000 & 0.00560000 & 1.27170000 \\
\hline 014 & -0.29030000 & 0.00120000 & -2.26820000 \\
\hline 012 & -0.33720000 & 0.00510000 & 2.27890000 \\
\hline N15 & -0.28360000 & -0.00350000 & 0.00580000 \\
\hline $\mathrm{C} 16$ & -1.73340000 & 0.00230000 & -0.00530000 \\
\hline C17 & -2.41080000 & 1.23270000 & -0.04580000 \\
\hline C18 & -2.42070000 & -1.22300000 & 0.01960000 \\
\hline C19 & -3.80880000 & 1.21250000 & -0.06460000 \\
\hline $\mathrm{C} 20$ & -3.81850000 & -1.19270000 & 0.00180000 \\
\hline $\mathrm{C} 21$ & -4.50980000 & 0.01250000 & -0.04120000 \\
\hline $\mathrm{H} 19$ & -4.35600000 & 2.14850000 & -0.09680000 \\
\hline $\mathrm{H} 20$ & -4.37330000 & -2.12450000 & 0.02070000 \\
\hline $\mathrm{H} 21$ & -5.59480000 & 0.01650000 & -0.05560000 \\
\hline $\mathrm{C} 22$ & -1.69560000 & -2.56260000 & 0.06540000 \\
\hline $\mathrm{H} 22$ & -0.62320000 & -2.36330000 & 0.06670000 \\
\hline $\mathrm{C} 23$ & -1.67510000 & 2.56690000 & -0.07020000 \\
\hline $\mathrm{H} 23$ & -0.60460000 & 2.35960000 & -0.04360000 \\
\hline $\mathrm{C} 24$ & -2.01410000 & -3.33480000 & 1.35940000 \\
\hline $\mathrm{H} 24 \mathrm{a}$ & -1.77260000 & -2.73550000 & 2.24010000 \\
\hline $\mathrm{H} 24 \mathrm{~b}$ & -3.07300000 & -3.60730000 & 1.41240000 \\
\hline $\mathrm{H} 24 \mathrm{c}$ & -1.42890000 & -4.25870000 & 1.40310000 \\
\hline $\mathrm{C} 25$ & -1.99510000 & -3.41360000 & -1.18290000 \\
\hline $\mathrm{H} 25 \mathrm{a}$ & -1.73360000 & -2.87400000 & -2.09610000 \\
\hline $\mathrm{H} 25 \mathrm{~b}$ & -1.41530000 & -4.34160000 & -1.15690000 \\
\hline $\mathrm{H} 25 \mathrm{c}$ & -3.05440000 & -3.68350000 & -1.23960000 \\
\hline $\mathrm{C} 26$ & -2.00030000 & 3.41730000 & 1.17210000 \\
\hline $\mathrm{H} 26 \mathrm{a}$ & -3.05800000 & 3.69770000 & 1.20040000 \\
\hline $\mathrm{H} 26 \mathrm{~b}$ & -1.76900000 & 2.87230000 & 2.09000000 \\
\hline $\mathrm{H} 26 \mathrm{c}$ & -1.41030000 & 4.33920000 & 1.16490000 \\
\hline $\mathrm{C} 27$ & -1.95430000 & 3.34410000 & -1.37030000 \\
\hline $\mathrm{H} 27 \mathrm{a}$ & -1.35990000 & 4.26270000 & -1.39760000 \\
\hline $\mathrm{H} 27 \mathrm{~b}$ & -1.69680000 & 2.74380000 & -2.24600000 \\
\hline $\mathrm{H} 27 \mathrm{c}$ & -3.00900000 & 3.62640000 & -1.44900000 \\
\hline $\mathrm{H} 3 \mathrm{~b}$ & 4.27660000 & -1.17070000 & -2.98320000 \\
\hline
\end{tabular}


F.6. carbo-[NMI(H)]-

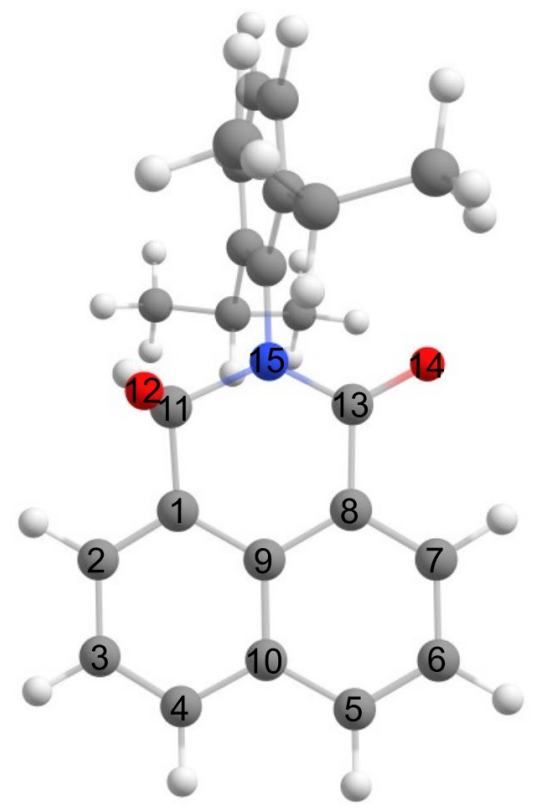

Figure S20. Calculated structure of carbo- $[\mathrm{NMI}(\mathrm{H})]^{-}$at the at the $\mathrm{B} 3 \mathrm{LYP} / 6-311 \mathrm{G}+(\mathrm{d}, \mathrm{p})$ level of theory. Selected interatomic distances ( $\AA$ ): C1-C2 1.380, C2-C3 1.413, C3-C4 1.377, C4-C10 1.419, C10-C5 1.419, C5-C6 1.376, C6-C7 1.411, C7-C8 1.380, C8-C9 1.424, C9-C10 1.432, C9-C1 1.419, C1-C11 1.531, C11-O12 1.305, C13-O14 1.241, C2-C1-C11-012 79.5․

Table S7. Coordinates of carbo-[NMI(H)] $]^{-}$optimized at the B3LYP/6-311G+(d,p) level of theory used for GIAO NMR calculations.

\begin{tabular}{|l|c|c|c|}
\hline Atom & $x$ & $y$ & $z$ \\
\hline C7 & 2.61870000 & 1.10360000 & -2.12290000 \\
\hline C8 & 1.87620000 & 0.42440000 & -1.17910000 \\
\hline C9 & 2.53680000 & -0.14650000 & -0.06080000 \\
\hline C10 & 3.96510000 & -0.09560000 & 0.02870000 \\
\hline C5 & 4.69080000 & 0.59200000 & -0.97880000 \\
\hline C6 & 4.02470000 & 1.19630000 & -2.02080000 \\
\hline H7 & 2.11290000 & 1.54040000 & -2.97830000 \\
\hline C1 & 1.79330000 & -0.75600000 & 0.98970000 \\
\hline H5 & 4.60420000 & -0.72630000 & 1.12780000 \\
\hline H6 & 5.77330000 & 0.63760000 & -0.91130000 \\
\hline C3 & 4.58160000 & 1.73270000 & -2.78260000 \\
\hline C2 & 3.86510000 & -1.35810000 & 2.10200000 \\
\hline
\end{tabular}




\begin{tabular}{|c|c|c|c|}
\hline $\mathrm{H} 4$ & 5.68800000 & -0.69960000 & 1.18970000 \\
\hline H3 & 4.36370000 & -1.84140000 & 2.93560000 \\
\hline $\mathrm{H} 2$ & 1.86580000 & -1.80250000 & 2.83280000 \\
\hline $\mathrm{C} 13$ & 0.39630000 & 0.13770000 & -1.44540000 \\
\hline C11 & 0.29390000 & -0.66010000 & 1.04150000 \\
\hline $\mathrm{O} 14$ & 0.21730000 & -0.88370000 & -2.23750000 \\
\hline $\mathrm{O} 12$ & -0.31650000 & -1.06010000 & 2.04590000 \\
\hline N15 & -0.30150000 & -0.05690000 & -0.01240000 \\
\hline C16 & -1.71830000 & 0.15710000 & 0.01500000 \\
\hline C17 & -2.19110000 & 1.46030000 & 0.28410000 \\
\hline $\mathrm{C} 18$ & -2.61790000 & -0.89530000 & -0.26000000 \\
\hline C19 & -3.57020000 & 1.69210000 & 0.27480000 \\
\hline $\mathrm{C} 20$ & -3.98850000 & -0.61430000 & -0.25250000 \\
\hline $\mathrm{C} 21$ & -4.46740000 & 0.66460000 & 0.00850000 \\
\hline $\mathrm{H} 19$ & -3.94740000 & 2.68790000 & 0.48370000 \\
\hline $\mathrm{H} 2 \mathrm{O}$ & -4.69420000 & -1.41260000 & -0.45670000 \\
\hline $\mathrm{H} 21$ & -5.53520000 & 0.85910000 & 0.00520000 \\
\hline $\mathrm{C} 22$ & -2.15030000 & -2.31890000 & -0.53610000 \\
\hline $\mathrm{H} 22$ & -1.06450000 & -2.29300000 & -0.61580000 \\
\hline $\mathrm{C} 23$ & -1.24100000 & 2.60390000 & 0.62450000 \\
\hline $\mathrm{H} 23$ & -0.22540000 & 2.23560000 & 0.47400000 \\
\hline $\mathrm{C} 24$ & -2.54130000 & -3.26490000 & 0.61610000 \\
\hline $\mathrm{H} 24 \mathrm{a}$ & -2.14360000 & -2.90420000 & 1.56700000 \\
\hline $\mathrm{H} 24 \mathrm{~b}$ & -3.63000000 & -3.35410000 & 0.70740000 \\
\hline $\mathrm{H} 24 \mathrm{c}$ & -2.14010000 & -4.26790000 & 0.43360000 \\
\hline $\mathrm{C} 25$ & -2.67040000 & -2.84530000 & -1.88560000 \\
\hline H25a & -2.34970000 & -2.19150000 & -2.69890000 \\
\hline $\mathrm{H} 25 \mathrm{~b}$ & -2.26540000 & -3.84440000 & -2.07710000 \\
\hline $\mathrm{H} 25 \mathrm{c}$ & -3.76330000 & -2.92220000 & -1.90370000 \\
\hline $\mathrm{C} 26$ & -1.36810000 & 3.00860000 & 2.10630000 \\
\hline $\mathrm{H} 26 \mathrm{a}$ & -2.36360000 & 3.40970000 & 2.32370000 \\
\hline $\mathrm{H} 26 \mathrm{~b}$ & -1.20120000 & 2.15080000 & 2.76230000 \\
\hline $\mathrm{H} 26 \mathrm{c}$ & -0.63290000 & 3.78030000 & 2.35820000 \\
\hline $\mathrm{C} 27$ & -1.43070000 & 3.82200000 & -0.29710000 \\
\hline $\mathrm{H} 27 \mathrm{a}$ & -0.68450000 & 4.59030000 & -0.06970000 \\
\hline $\mathrm{H} 27 \mathrm{~b}$ & -1.31910000 & 3.54190000 & -1.34780000 \\
\hline $\mathrm{H} 27 \mathrm{c}$ & -2.41940000 & 4.27510000 & -0.17360000 \\
\hline $\mathrm{H} 11$ & -0.09120000 & 1.08940000 & -1.76530000 \\
\hline
\end{tabular}




\section{G. NMR Chemical Shift and Absolute Chemical Shielding Calculations}

\section{G.1. ${ }^{1} \mathrm{H}$ NMR Calculations}

To provide an accurate NMR prediction, an experimental chemical shift ( $\delta$ ) vs. absolute chemical shielding $(\sigma)$ plot was generated using the parent $\mathrm{NMI}$ as a calibration standard to minimize errors due to basis set effects. Linear regression between absolute chemical shielding $(\sigma)$ and experimental shift $(\delta)$ yielded $\sigma=-1.1319 * \delta+32.287$. This relationship was used to predict the ${ }^{1} \mathrm{H}$ NMR experimental chemical shifts of the ortho, meta, para and carbo hydride addition isomers of NMI. Due to the poor solubility of NMI in benzene, the only the protons of the isopropyl group, and ortho and para hydrogens of the naphthalene ring were included in the experimental fit. The atom numbering scheme used below is taken from Figure S12; hydrogen atom identity is based upon carbon atom attachment.

Table S8. Calculated absolute chemical shielding $\sigma$ vs. experimental ${ }^{1} \mathrm{H}$ NMR chemical shift $\delta$ of $\mathrm{NMI}$ in benzene- $d_{6}(\mathrm{ppm})$. iPr $=$ isopropyl.

\begin{tabular}{|c|c|c|}
\hline Entry & Experimental Chemical Shift $(\delta)$ & Calculated Shielding $(\sigma)$ \\
\hline $\mathrm{iPr} \mathrm{CH}_{3}$ & 1.2 & 30.8 \\
\hline iPr CH & 2.96 & 29.19 \\
\hline Naphthalene para $\mathrm{H}$ & 7.45 & 23.43 \\
\hline Naphthalene orthoH & 8.56 & 22.90 \\
\hline
\end{tabular}

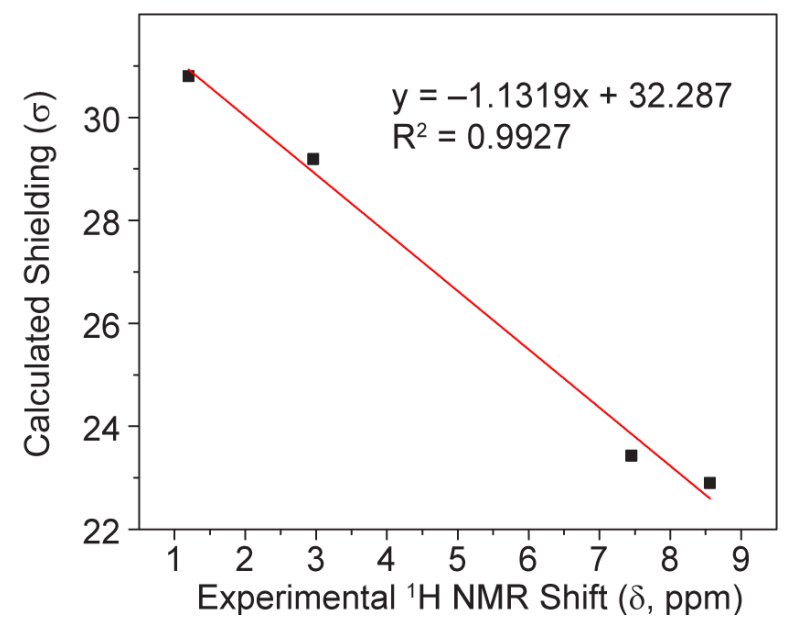

Figure S21. Experimental ${ }^{1} \mathrm{H}$ NMR chemical shifts $(\delta)$ vs. calculated absolute chemical shielding $(\sigma)$ of NMI. 
Table S9. Calculated absolute chemical shielding $\sigma$ vs. predicted ${ }^{1} \mathrm{H}$ NMR chemical shift $\delta$ of ortho-[NMI(H)] ${ }^{-}$ in benzene- $d_{6}(\mathrm{ppm})$. iPr = isopropyl.

\begin{tabular}{|l|c|c|}
\hline Entry & Calculated Shielding $(\sigma)$ & Predicted $(\delta)$ \\
\hline $\mathrm{iPr} \mathrm{CH}_{3} \times 12$ & 30.87 & 1.25 \\
\hline $\mathrm{iPr} \mathrm{CH} \times 2$ & 29.14 & 2.78 \\
\hline $\mathrm{C}(2)-H \times 2$ & 27.93 & 3.85 \\
\hline $\mathrm{C}(3)-H$ & 26.03 & 5.53 \\
\hline $\mathrm{C}(6)-H$ & 25.82 & 5.71 \\
\hline $\mathrm{C}(4)-H$ & 25.61 & 5.90 \\
\hline $\mathrm{C}(5)-H$ & 25.48 & 6.01 \\
\hline $\operatorname{PhiPr}_{2} \mathrm{C}-H \times 2$ & 24.75 & 6.66 \\
\hline $\operatorname{PhiPr}_{2} \mathrm{C}-H \times 1$ & 24.60 & 6.79 \\
\hline $\mathrm{C}(7)-H$ & 24.11 & 7.22 \\
\hline
\end{tabular}

Table S10. Calculated absolute chemical shielding $\sigma$ vs. predicted ${ }^{1} \mathrm{H}$ NMR chemical shift $\delta$ of para-[NMI(H)] ${ }^{-}$ in benzene- $d_{6}(\mathrm{ppm})$. iPr $=$ isopropyl.

\begin{tabular}{|l|c|c|}
\hline Entry & Calculated Shielding $(\sigma)$ & Predicted $(\delta)$ \\
\hline$i \operatorname{Pr} \mathrm{CH}_{3} \times 12$ & 30.90 & 1.23 \\
\hline $\mathrm{iPr} \mathrm{CH} \times 2$ & 29.10 & 2.82 \\
\hline $\mathrm{C}(4)-H \times 2$ & 27.90 & 4.05 \\
\hline $\mathrm{C}(3)-H$ & 27.16 & 4.53 \\
\hline $\mathrm{C}(6)-H$ & 25.40 & 6.08 \\
\hline $\mathrm{C}(5)-H$ & 25.05 & 6.39 \\
\hline $\mathrm{C}(2)-H$ & 24.85 & 6.57 \\
\hline $\operatorname{PhiPr}_{2} \mathrm{C}-H \times 2$ & 24.77 & 6.64 \\
\hline $\operatorname{PhiPr}_{2} \mathrm{C}-H \times 1$ & 24.62 & 6.77 \\
\hline $\mathrm{C}(7)-H$ & 24.00 & 7.32 \\
\hline
\end{tabular}


Table S11. Calculated absolute chemical shielding $\sigma$ vs. predicted ${ }^{1} \mathrm{H}$ NMR chemical shift $\delta$ of meta$[\mathrm{NMI}(\mathrm{H})]^{-}$in benzene- $d_{6}(\mathrm{ppm}) . \mathrm{iPr}=$ isopropyl, avg = protons are not strictly chemically equivalent but are averaged.

\begin{tabular}{|l|c|c|}
\hline Entry & Calculated Shielding $(\sigma)$ & Predicted $(\delta)$ \\
\hline iPr CH$H_{3} \times 12$ & 30.90 & 1.23 \\
\hline $\mathrm{C}(4)-H$ & 29.57 & 2.40 \\
\hline $\mathrm{iPr} \mathrm{CH}$ 2 & 29.24 & 2.69 \\
\hline $\mathrm{C}(7)-H$ & 27.05 & 4.62 \\
\hline $\mathrm{C}(5)-H$ & 26.95 & 4.72 \\
\hline $\mathrm{C}(6)-H$ & 26.47 & 5.14 \\
\hline $\mathrm{C}(2)-H$ & 26.04 & 5.52 \\
\hline $\mathrm{C}(3)-H$ (avg) & 25.80 & 5.73 \\
\hline $\operatorname{PhiPr}_{2} \mathrm{C}-H \times 2$ & 24.78 & 6.63 \\
\hline $\operatorname{PhiPr}_{2} \mathrm{C}-H \times 1$ & 24.59 & 6.80 \\
\hline
\end{tabular}

Table S12. Calculated absolute chemical shielding $\sigma$ vs. predicted ${ }^{1} \mathrm{H}$ NMR chemical shift $\delta$ of carbo$[\mathrm{NMI}(\mathrm{H})]^{-}$in benzene- $d_{6}(\mathrm{ppm}) . \mathrm{iPr}=$ isopropyl, avg = protons are not strictly chemically equivalent but are averaged.

\begin{tabular}{|l|c|c|}
\hline Entry & Calculated Shielding $(\sigma)$ & Predicted $(\delta)$ \\
\hline iPr $\mathrm{CH}_{3} \times 12$ (avg) & 30.83 & 1.29 \\
\hline $\mathrm{iPr} \mathrm{CH}$ & 28.57 & 3.28 \\
\hline $\mathrm{iPr} \mathrm{CH}$ & 27.80 & 3.96 \\
\hline $\mathrm{PhiPr}_{2} \mathrm{C}-H$ & 24.73 & 6.68 \\
\hline $\mathrm{PhiPr}_{2} \mathrm{C}-H$ & 24.64 & 6.76 \\
\hline $\mathrm{PhiPr}_{2} \mathrm{C}-H$ & 24.62 & 6.77 \\
\hline $\mathrm{C}(11)-H$ & 24.57 & 6.81 \\
\hline $\mathrm{C}(3)-H$ & 24.37 & 6.99 \\
\hline $\mathrm{C}(2)-H$ & 24.35 & 7.01 \\
\hline $\mathrm{C}(6)-H$ & 24.32 & 7.04 \\
\hline $\mathrm{C}(4)-H$ & 24.18 & 7.16 \\
\hline $\mathrm{C}(5)-H$ & 23.91 & 7.40 \\
\hline $\mathrm{C}(7)-H$ & 23.22 & 8.01 \\
\hline
\end{tabular}




\section{G.2. ${ }^{13} \mathrm{C}$ NMR Calculations}

To provide an accurate NMR prediction, an experimental chemical shift $(\delta)$ vs. absolute chemical shielding $(\sigma)$ plot was generated using the parent $\mathrm{NMI}$ as a calibration standard to minimize errors due to basis set effects. Linear regression between absolute chemical shielding $(\sigma)$ and experimental shift $(\delta)$ yielded $\sigma=-1.0284 * \delta+180.73$. This relationship was used to predict the ${ }^{13} \mathrm{C}$ NMR experimental chemical shifts of the ortho, meta, para and carbo hydride addition isomers of NMI. Due to the poor solubility of $\mathrm{NMI}$ in benzene, the experimental ${ }^{13} \mathrm{C}$ shifts of $\mathrm{NMI}$ were taken from a ${ }^{13} \mathrm{C}$ spectrum acquired in chloroform. The atom numbering scheme used below is taken from Figure S12.

Table S13. Calculated absolute chemical shielding $\sigma$ vs. experimental ${ }^{13} \mathrm{C}$ NMR chemical shift $\delta$ of NMI in chloroform- $d(\mathrm{ppm})$. i $\mathrm{Pr}=$ isopropyl.

\begin{tabular}{|c|c|c|}
\hline Entry & Experimental Chemical Shift $(\delta)$ & Calculated Shielding $(\sigma)$ \\
\hline iPr Cof $\mathrm{CH}_{3}$ & 24.13 & 157.93 \\
\hline iPr C of $\mathrm{CH}$ & 29.26 & 148.21 \\
\hline$C(1)+C(8)$ & 122.91 & 54.34 \\
\hline $\mathrm{PhiPr}_{2} \mathrm{C}$ of $\mathrm{Ph} \mathrm{C}-H \times 2$ & 124.16 & 54.10 \\
\hline$C(3)+C(6)$ & 127.18 & 51.18 \\
\hline $\mathrm{PhiPr}_{2} \mathrm{C}$ of $\mathrm{Ph} \mathrm{C}-H \times 1$ & 129.63 & 48.76 \\
\hline$C(9)$ or $C(10)$ & 128.96 & 48.19 \\
\hline$C(9)$ or $C(10)$ & 130.99 & 46.03 \\
\hline$C(2)+C(7)$ & 131.88 & 45.48 \\
\hline$C 4)+C(5)$ & 134.32 & 43.03 \\
\hline $\mathrm{PhiPr}_{2} \mathrm{C}$ & 131.98 & 42.9 \\
\hline $\mathrm{PhiPr}_{2} \mathrm{C}$ of $\mathrm{C}-\mathrm{iPr}$ & 145.81 & 28.16 \\
\hline$C(11)+C(13)$ & 164.32 & 12.36 \\
\hline
\end{tabular}




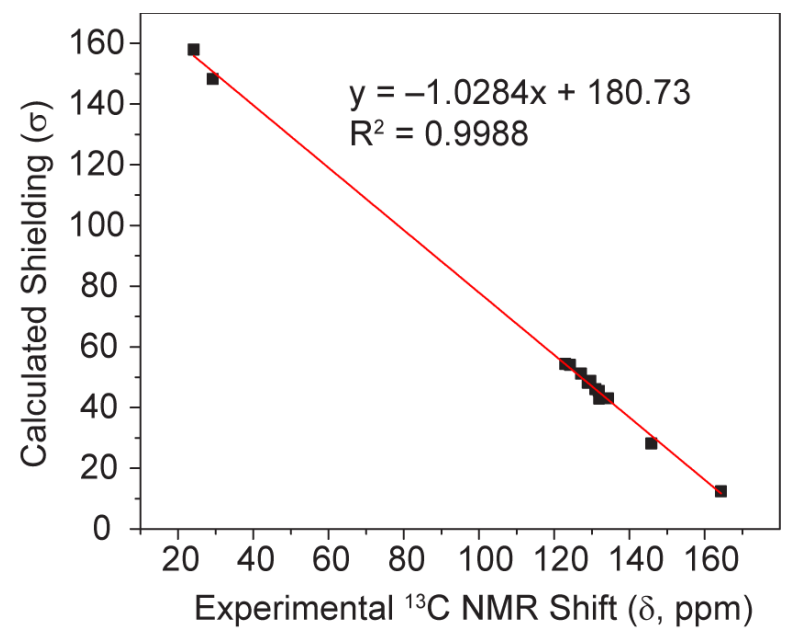

Figure S22. Experimental ${ }^{13} \mathrm{C}$ NMR chemical shifts $(\delta)$ vs. calculated absolute chemical shielding $(\sigma)$ of NMI.

Table S14. Selected calculated absolute chemical shielding $\sigma$ vs. predicted ${ }^{13} \mathrm{C}$ NMR chemical shifts $\delta$ of ortho- $[\mathrm{NMI}(\mathrm{H})]^{-}$in benzene- $d_{6}(\mathrm{ppm})$.

\begin{tabular}{|c|c|c|}
\hline Entry & Calculated Shift $(\sigma)$ & Predicted $(\boldsymbol{\delta})$ \\
\hline C2 & 148.58 & 31.26 \\
\hline C6 & 68.27 & 109.35 \\
\hline C5 & 58.27 & 119.08 \\
\hline C7 & 49.05 & 128.04 \\
\hline C4 & 48.76 & 128.33 \\
\hline C3 & 48.33 & 128.74 \\
\hline C11 & 16.33 & 159.86 \\
\hline C13 & 13.18 & 162.93 \\
\hline
\end{tabular}

Table S15. Selected calculated absolute chemical shielding $\sigma$ vs. predicted ${ }^{13} \mathrm{C}$ NMR chemical shifts $\delta$ of para- $[\mathrm{NMI}(\mathrm{H})]^{-}$in benzene- $d_{6}(\mathrm{ppm})$.

\begin{tabular}{|l|c|c|}
\hline Entry & Calculated Shielding $(\sigma)$ & Predicted $(\delta)$ \\
\hline C4 & 146.30 & 33.48 \\
\hline C3 & 73.00 & 104.76 \\
\hline C6 & 63.80 & 113.70 \\
\hline C7 & 51.61 & 125.55 \\
\hline C2 & 49.00 & 128.09 \\
\hline C5 & 48.88 & 128.21 \\
\hline C11 & 17.58 & 158.64 \\
\hline C13 & 12.01 & 164.06 \\
\hline
\end{tabular}


Table S16. Selected calculated absolute chemical shielding $\sigma$ vs. predicted ${ }^{13} \mathrm{C}$ NMR chemical shifts $\delta$ of meta- $[\mathrm{NMI}(\mathrm{H})]^{-}$in benzene- $d_{6}(\mathrm{ppm})$.

\begin{tabular}{|l|c|c|}
\hline Entry & Calculated Shielding $(\boldsymbol{\sigma})$ & Predicted $(\boldsymbol{\delta})$ \\
\hline C3 & 138.66 & 40.91 \\
\hline C4 & 111.24 & 67.57 \\
\hline C7 & 83.67 & 94.38 \\
\hline C2 & 47.90 & 129.16 \\
\hline C6 & 49.34 & 127.76 \\
\hline C5 & 60.29 & 117.14 \\
\hline C11 & 10.57 & 165.46 \\
\hline C13 & 9.48 & 166.52 \\
\hline
\end{tabular}

Table S17. Selected calculated absolute chemical shielding $\sigma$ vs. predicted ${ }^{13} \mathrm{C}$ NMR chemical shifts $\delta$ of carbo- $[\mathrm{NMI}(\mathrm{H})]^{-}$in benzene- $d_{6}(\mathrm{ppm})$.

\begin{tabular}{|l|c|c|}
\hline Entry & Calculated Shielding $(\sigma)$ & Predicted $(\delta)$ \\
\hline C11 & 71.41 & 106.30 \\
\hline C4 & 56.54 & 120.76 \\
\hline C2 & 54.97 & 122.29 \\
\hline C6 & 54.32 & 122.92 \\
\hline C7 & 53.10 & 124.11 \\
\hline C3 & 52.50 & 124.69 \\
\hline C5 & 49.56 & 127.55 \\
\hline C13 & 13.13 & 162.97 \\
\hline
\end{tabular}

\section{G.3. Analysis of the Experimental NMR Spectra Based upon ${ }^{1} \mathrm{H}$ and ${ }^{13} \mathrm{C}$ NMR Calculations}

Addition of a hydride anion to $\mathrm{NMI}$ is predicted to make 4 possible isomers, designated ortho-

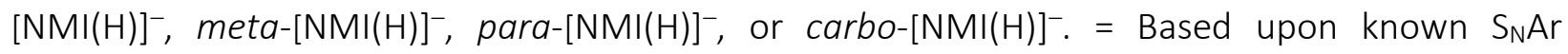
chemistry, it would be expected that the most likely outcome of the reaction of NMI with a hydride equivalent is the formation of either the ortho- $[\mathrm{NMI}(\mathrm{H})]^{-}$, para- $[\mathrm{NMI}(\mathrm{H})]^{-}$, or carbo- $[\mathrm{NMI}(\mathrm{H})]^{-}$ species. To assist in the identification of the species present in Figure S10, ${ }^{1} \mathrm{H}$ and ${ }^{13} \mathrm{C} N M R$ calculations were utilized to predict the NMR spectra of the possible isomers for comparison. The structures of the four isomers were optimized using the B3LYP functional and the $6311 \mathrm{G}+(\mathrm{d}, \mathrm{p})$ 
basis set with an IEFPCM benzene solvation shell to arrive at equilibrium structures. From these calculations, key ${ }^{1} \mathrm{H}$ and ${ }^{13} \mathrm{C}$ NMR chemical shifts were compared with the experimental spectra, shown below:

Table S18. ${ }^{1} \mathrm{H}$ and ${ }^{13} \mathrm{C}$ calculated chemical shifts of the relevant hydride protons or carbon atom which is directly bonded to the hydride equivalent.

\begin{tabular}{|c|c|}
\hline Species & Prediction (ppm) \\
\hline ortho-[NMI(H)]- $\left(\mathrm{H}_{2}\right)$ & 3.85 \\
\hline ortho-[NMI(H)] $]^{-}(\mathrm{C})$ & 31.26 \\
\hline meta-[NMI(H)]- $\left(\mathrm{H}_{2}\right)$ & 5.73 \\
\hline meta-[NMI(H)]-(C) & 40.91 \\
\hline para-[NMI(H)]- $\left(\mathrm{H}_{2}\right)$ & 4.05 \\
\hline para-[NMI(H)]- ${ }^{-}(\mathrm{C})$ & 33.48 \\
\hline carbo-[NMI(H)]- $(\mathrm{H})$ & 6.81 \\
\hline carbo-[NMI(H)]- $]^{-}(\mathrm{C})$ & 106.30 \\
\hline
\end{tabular}

Table S19. Diagnostic experimental ${ }^{1} \mathrm{H}$ and ${ }^{13} \mathrm{C}$ resonances of the product of treating $\mathrm{NMI}$ with a hydride equivalent (ppm, benzene- $\left.d_{6}\right)$.

\begin{tabular}{|l|c|}
\hline Entry & Chemical Shift (ppm) \\
\hline Experimental ${ }^{1} \mathrm{H}$ resonance of the hydride product & 4.10 \\
\hline Experimental ${ }^{1} \mathrm{H}$ resonance of the hydride product & 4.18 \\
\hline Experimental ${ }^{13} \mathrm{C}$ resonance of the hydride product & 27.7 \\
\hline Experimental ${ }^{13} \mathrm{C}$ resonance of the hydride product & 30.2 \\
\hline
\end{tabular}

Comparison of the calculated values in Table S12 with the experimental values obtained in Table S13 clearly implicate ortho- $[\mathrm{NMI}(\mathrm{H})]^{-}$and para- $[\mathrm{NMI}(\mathrm{H})]^{-}$as the likely products of the reaction of $\mathrm{NMI}$ with a hydride source or electrochemical $2 \mathrm{e}^{-}$reduction concomitant with protonation. While conclusive assignment of the resonances in Table S13 cannot be made from these calculations alone, the predicted $\mathrm{CH}_{2}{ }^{1} \mathrm{H}$ and ${ }^{13} \mathrm{C}$ resonances of the ortho isomer are calculated to be further upfield relative to the para isomer, leading to the following tentative assignment below: 


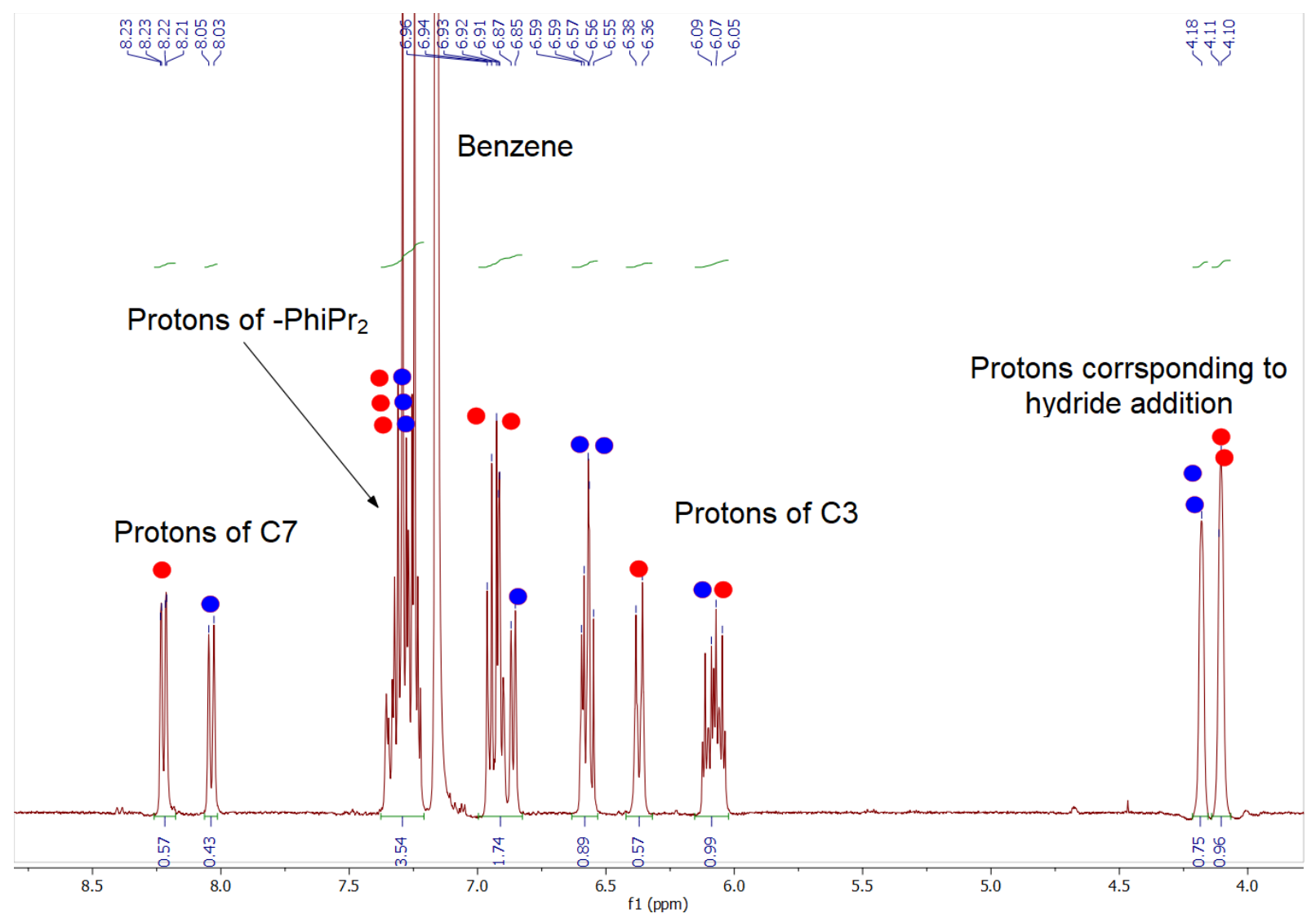

Figure S23. Tentative assignment of the ${ }^{1} \mathrm{H}$ spectrum in Figure S10 considering the calculated NMR predictions. The red dots correspond to ortho- $[\mathrm{NMI}(\mathrm{H})]^{-}$while the blue dots correspond to para- $[\mathrm{NMI}(\mathrm{H})]^{-}$. Each dot represents a proton. There is an apparent $\sim 57: 43$ ratio of ortho:para [NMI(H)] $]^{-}$isomers. 


\section{H. HOMO and LUMO Energy Levels and Latimer Diagram of [NMI(H)] $]^{-}$}

A

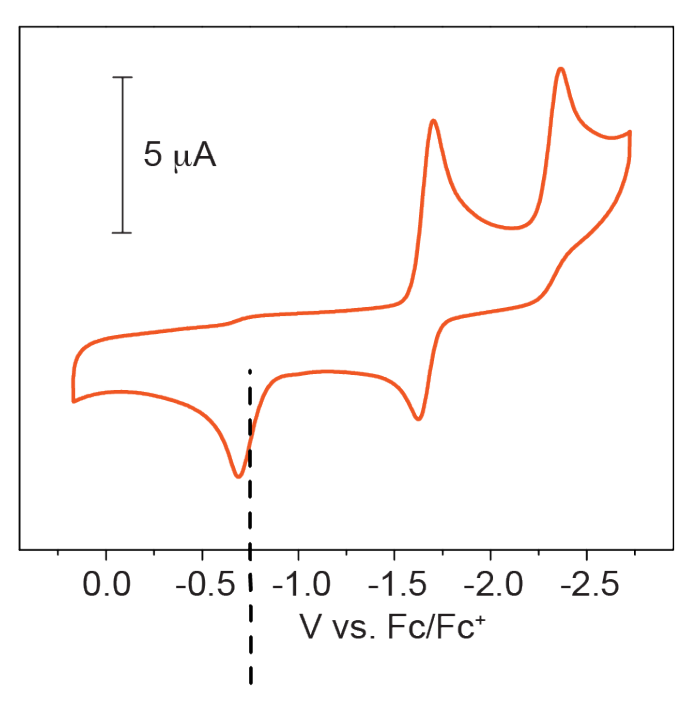

$\mathrm{HOMO}=-0.75 \mathrm{~V}$ vs. $\mathrm{Fc} / \mathrm{Fc}^{+}$ inflection point of reoxidation wave

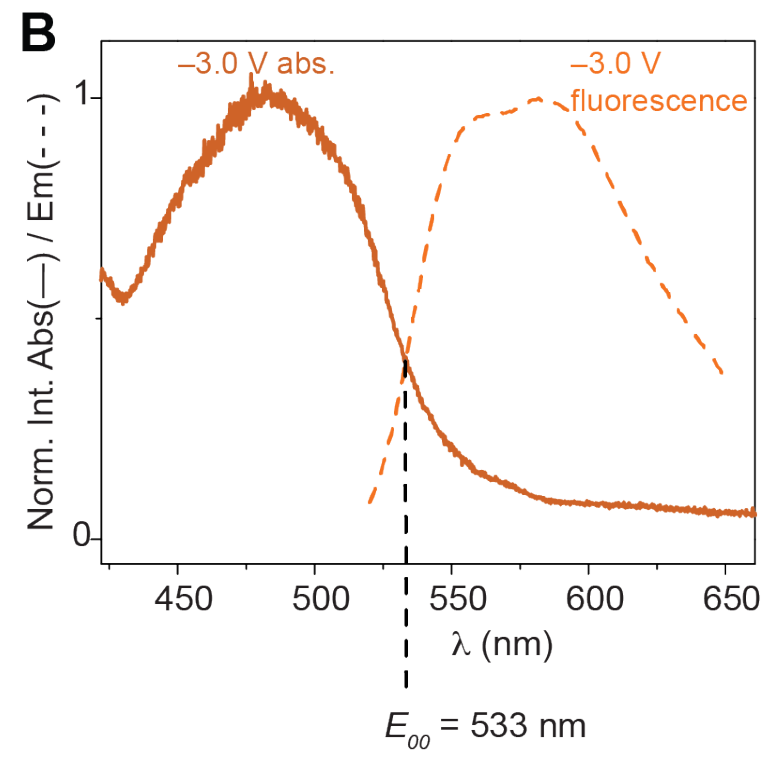

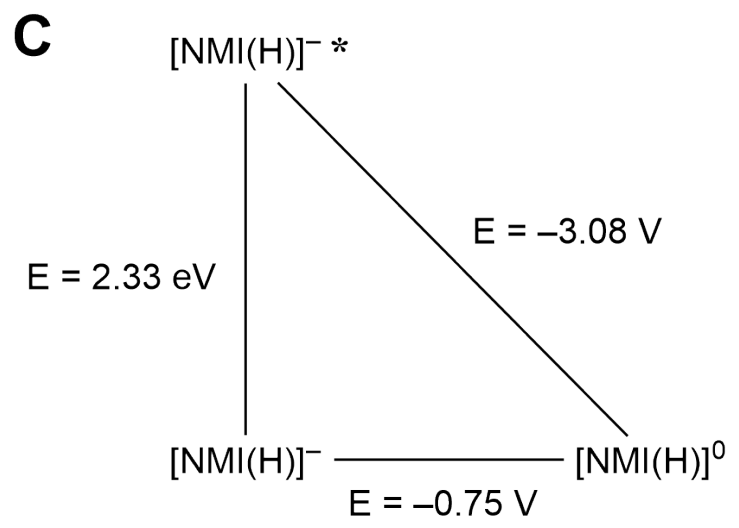

Figure S24. (A) Cyclic voltammogram of $1 \mathrm{mM} \mathrm{NMI} \mathrm{in} 100 \mathrm{mM}$ TBAPF 6 propylene carbonate solution. The scan rate was $100 \mathrm{mV} / \mathrm{s}$. A $1 \mathrm{~cm}^{2}$ glassy carbon working electrode, leak-free $\mathrm{Ag} / \mathrm{AgCl}$ reference electrode, and Pt mesh counter electrode were used. The HOMO energy level is approximated by the $[\mathrm{NMI}(\mathrm{H})]^{0 /-}$ reduction potential at $-0.75 \mathrm{~V}$ vs. $\mathrm{Fc} / \mathrm{Fc}^{+}$. (B) Overlay of the normalized absorbance (solid) and emission (dashed) spectra of $1 \mathrm{mM} \mathrm{NMI}$ in $100 \mathrm{mM} 100 \mathrm{mM} \mathrm{TBAPF}_{6}$ dimethyl acetamide solution after applying $3.0 \mathrm{~V}$ vs. $\mathrm{Fc} / \mathrm{Fc}^{+}$. The $E_{00}$ excited state energy of $[\mathrm{NMI}(\mathrm{H})]^{-*}$ is assigned as the overlap of the normalized absorption and emission spectra: $E_{00}=533 \mathrm{~nm}, 2.33 \mathrm{eV}$. (C) Latimer diagram of [NMI(H)] $]^{-}$to furnish the $[\mathrm{NMI}(\mathrm{H})]^{0 /-*}$ reduction potential of $-3.08 \mathrm{~V}$ vs. $\mathrm{Fc} / \mathrm{Fc}^{+}$. The energies of $\mathrm{NMI}[\mathrm{H}\}^{-}$are summarized on the energy level diagram of Figure 4 in main text. 


\section{Photoreactivity of [NMI(H)]-[TBA]+ with Methyl-4-Chlorobenzoate}

Inside a $\mathrm{N}_{2}$-filled glovebox, a stock solution consisting of [NMI(H)] $]^{-}[\mathrm{TBA}]^{+}$(30 $\mathrm{mg}, 0.051 \mathrm{mmol}$ ) and methyl-4-chlorobenzoate $\left(9 \mathrm{mg}, 0.051 \mathrm{mmol}\right.$ ) dissolved in $2.25 \mathrm{~mL} \mathrm{C}_{6} \mathrm{D}_{6}$ was prepared. To $3 \mathrm{~J}$ Young NMR tubes, $0.75 \mathrm{~mL}$ of the stock solution were added. One tube was sealed. To the second tube was added $0.075 \mathrm{~mL}$ (50 eq.) $\mathrm{N}$-methyl pyrrole, and the tube was then sealed. To the third tube was added $0.014 \mathrm{~mL}$ (5 equiv) triethylphosphite, and the tube was then sealed. Solutions in sealed J-Young tubes were brought out of the glovebox and allowed to sit for $2 \mathrm{~h}$ in the dark, then NMR spectra were acquired. Solutions were then illuminated with two $440 \mathrm{~nm}$ Kessil LED lamps while cooled by a fan. Post-reaction NMR spectra were then acquired after $2 \mathrm{~h}$ of illumination.

Scheme 1. Photoreactivity of $[\mathrm{NMI}(\mathrm{H})]^{-}[\mathrm{TBA}]^{+}$with methyl-4-chlorobenzoate, and with radical traps $\mathrm{N}$ methylpyrrole or triethylphosphite.

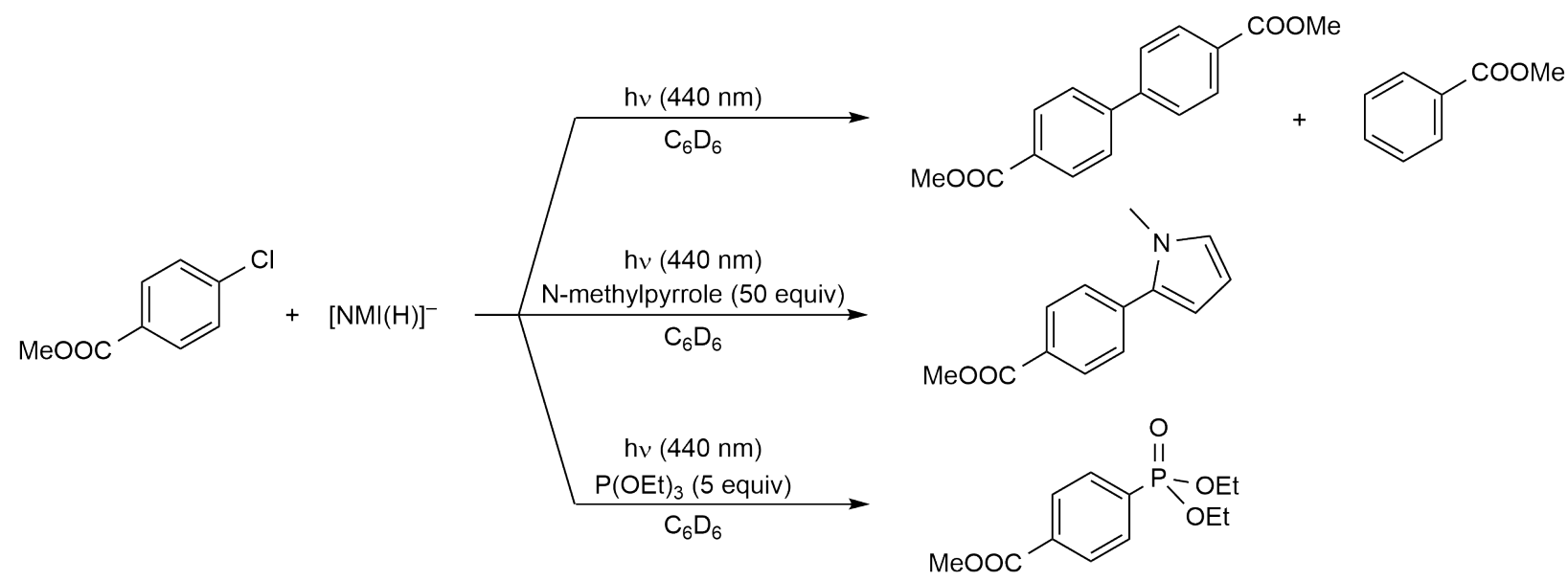



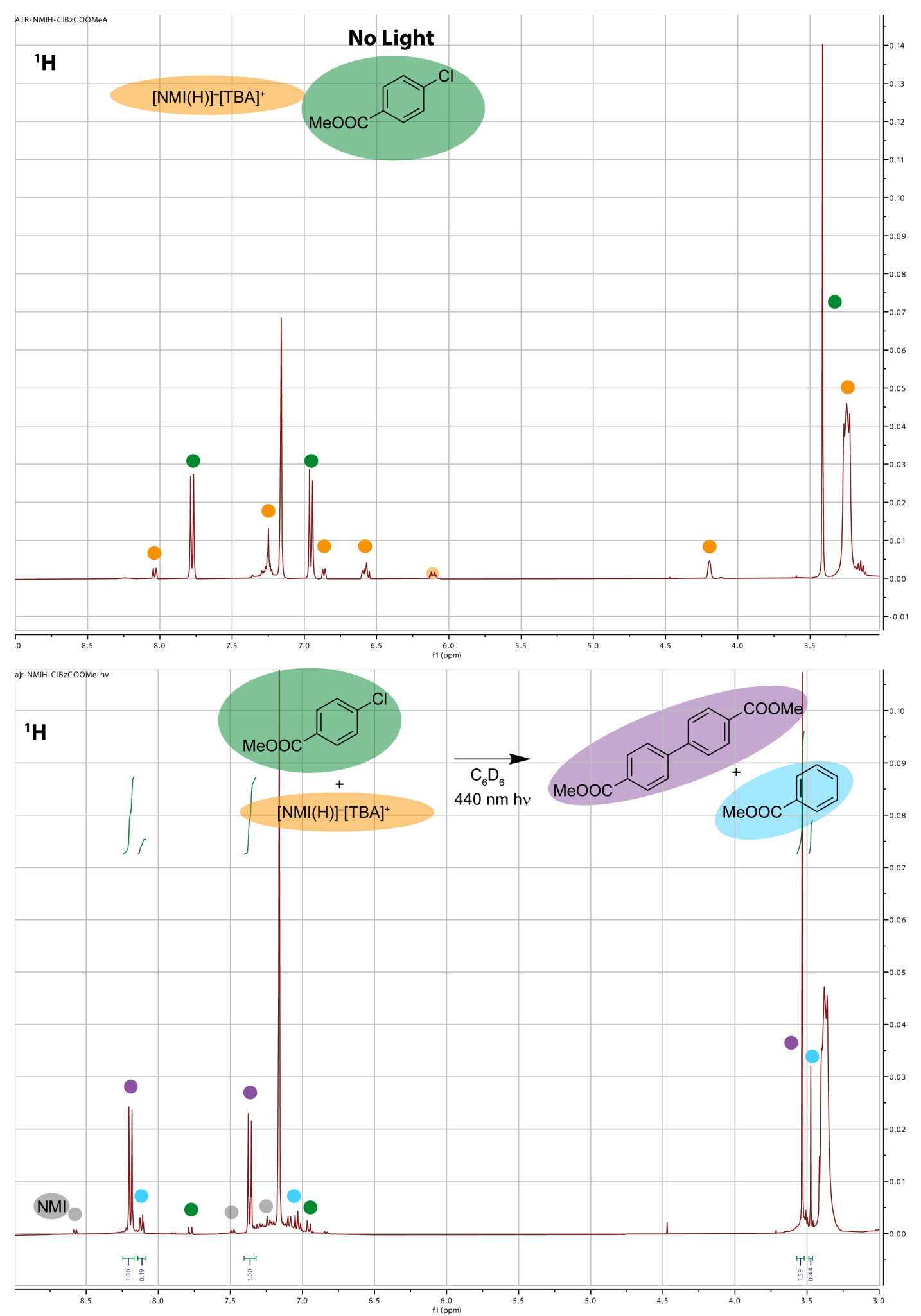

Figure S25. Top: NMR spectrum $\left({ }^{1} \mathrm{H}, 400 \mathrm{MHz}\right)$ of $[\mathrm{NMI}(\mathrm{H})]^{-}[\mathrm{TBA}]^{+}$and methyl-4-chlorobenzoate dissolved $\mathrm{C}_{6} \mathrm{D}_{6}$, after sitting in the dark for $2 \mathrm{~h}$ in a J-Young NMR tube. Bottom: NMR spectrum $\left({ }^{1} \mathrm{H}, 400 \mathrm{MHz}\right)$ of the same sample after illumination (440 $\mathrm{nm}$ ) for $2 \mathrm{~h}$. 

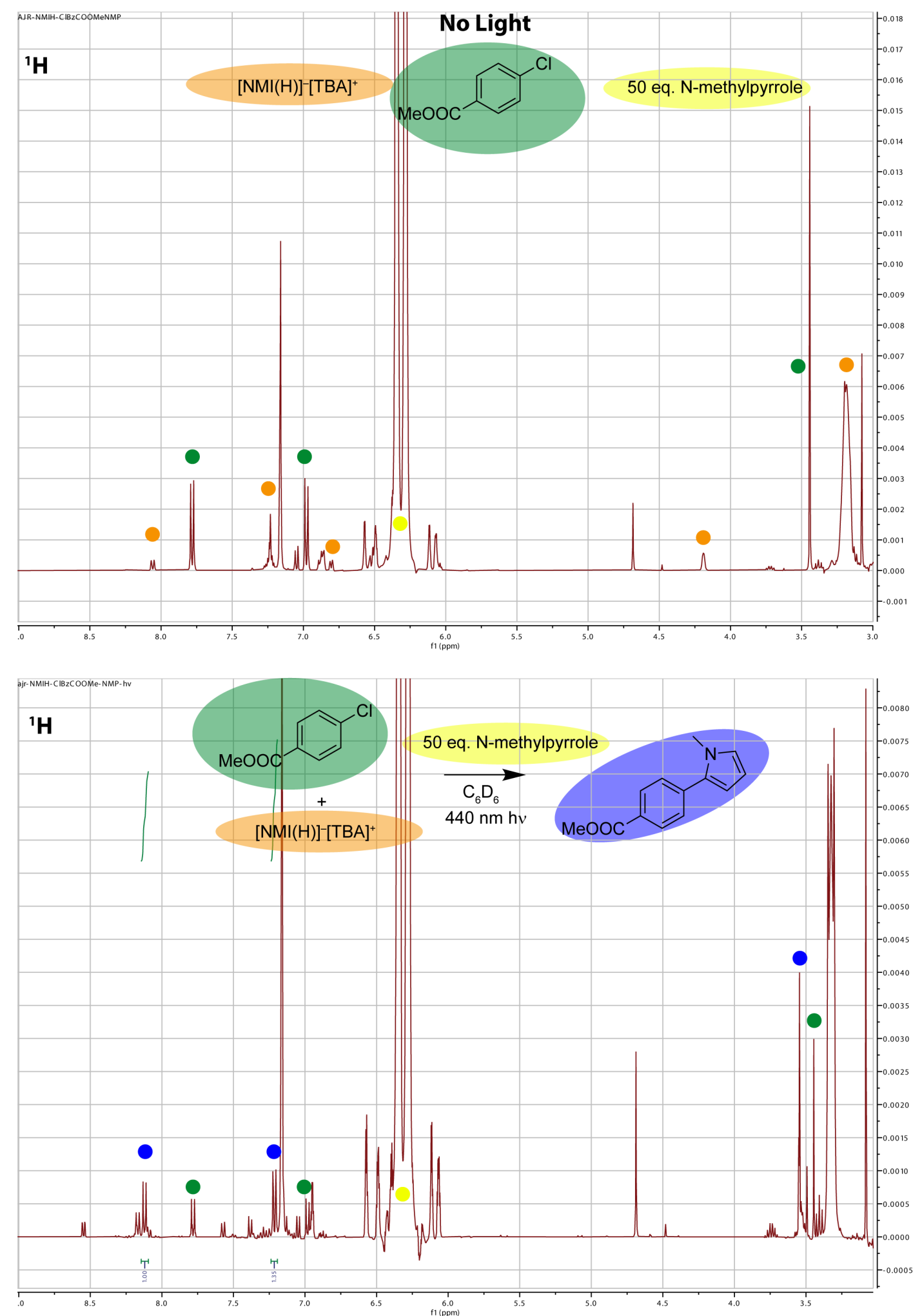

Figure S26. Top: NMR spectrum $\left({ }^{1} \mathrm{H}, 400 \mathrm{MHz}\right)$ of $[\mathrm{NMI}(\mathrm{H})]^{-}[\mathrm{TBA}]^{+}$, methyl-4-chlorobenzoate and $\mathrm{N}$-methyl pyrrole dissolved $\mathrm{C}_{6} \mathrm{D}_{6}$, after sitting in the dark for $2 \mathrm{~h}$ in a J-Young NMR tube. Bottom: NMR spectrum $\left({ }^{1} \mathrm{H}\right.$, $400 \mathrm{MHz}$ ) of the same sample after illumination (440 $\mathrm{nm}$ ) for $2 \mathrm{~h}$. 

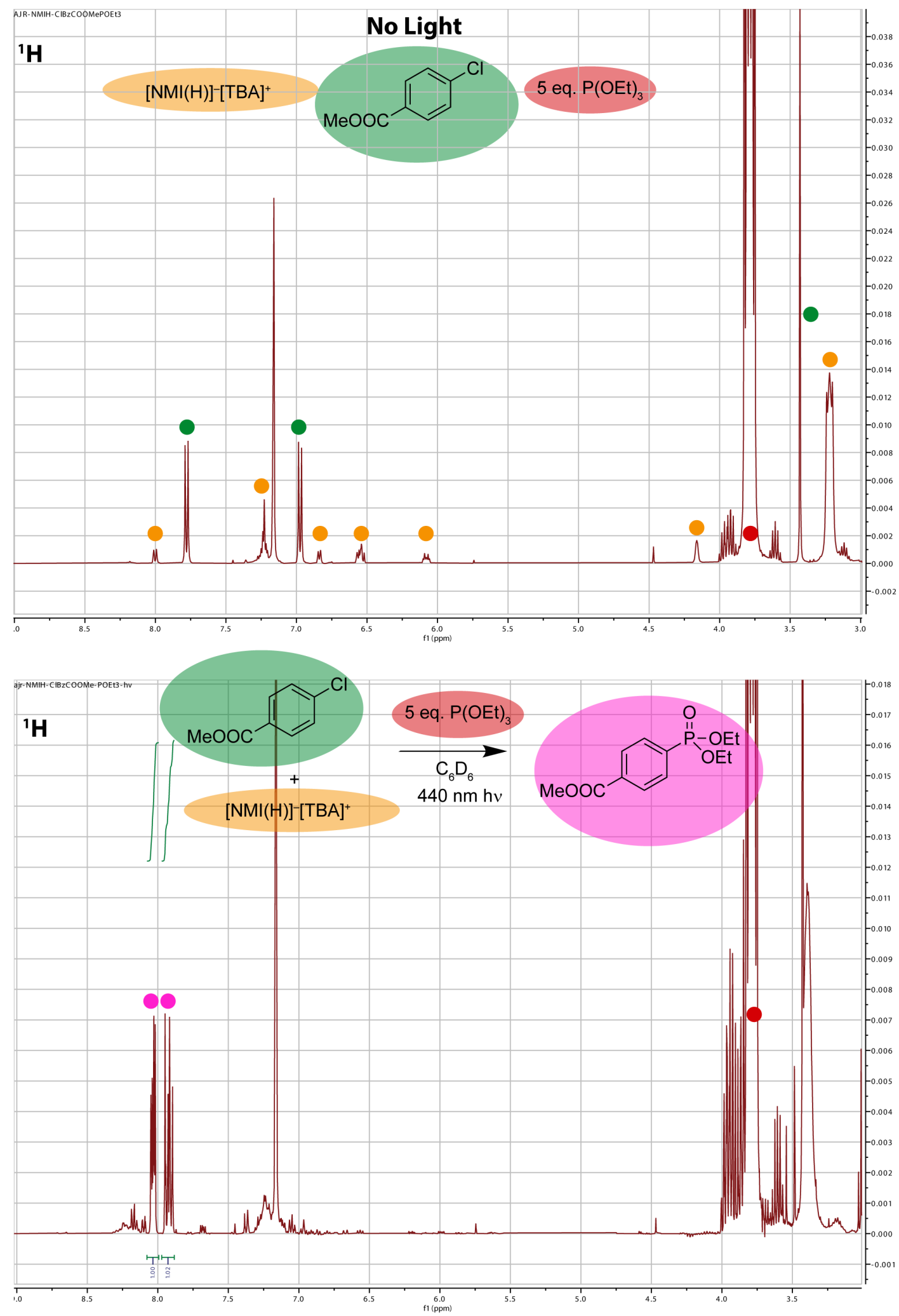

Figure S27. Top: NMR spectrum $\left({ }^{1} \mathrm{H}, 400 \mathrm{MHz}\right)$ of $[\mathrm{NMI}(\mathrm{H})]^{-}[\mathrm{TBA}]^{+}$, methyl-4-chlorobenzoate and $\mathrm{P}(\mathrm{OEt})_{3}$ dissolved $\mathrm{C}_{6} \mathrm{D}_{6}$, after sitting in the dark for $2 \mathrm{~h}$ in a J-Young NMR tube. Bottom: NMR spectrum $\left({ }^{1} \mathrm{H}, 400 \mathrm{MHz}\right)$ of the same sample after illumination (440 $\mathrm{nm}$ ) for $2 \mathrm{~h}$. 

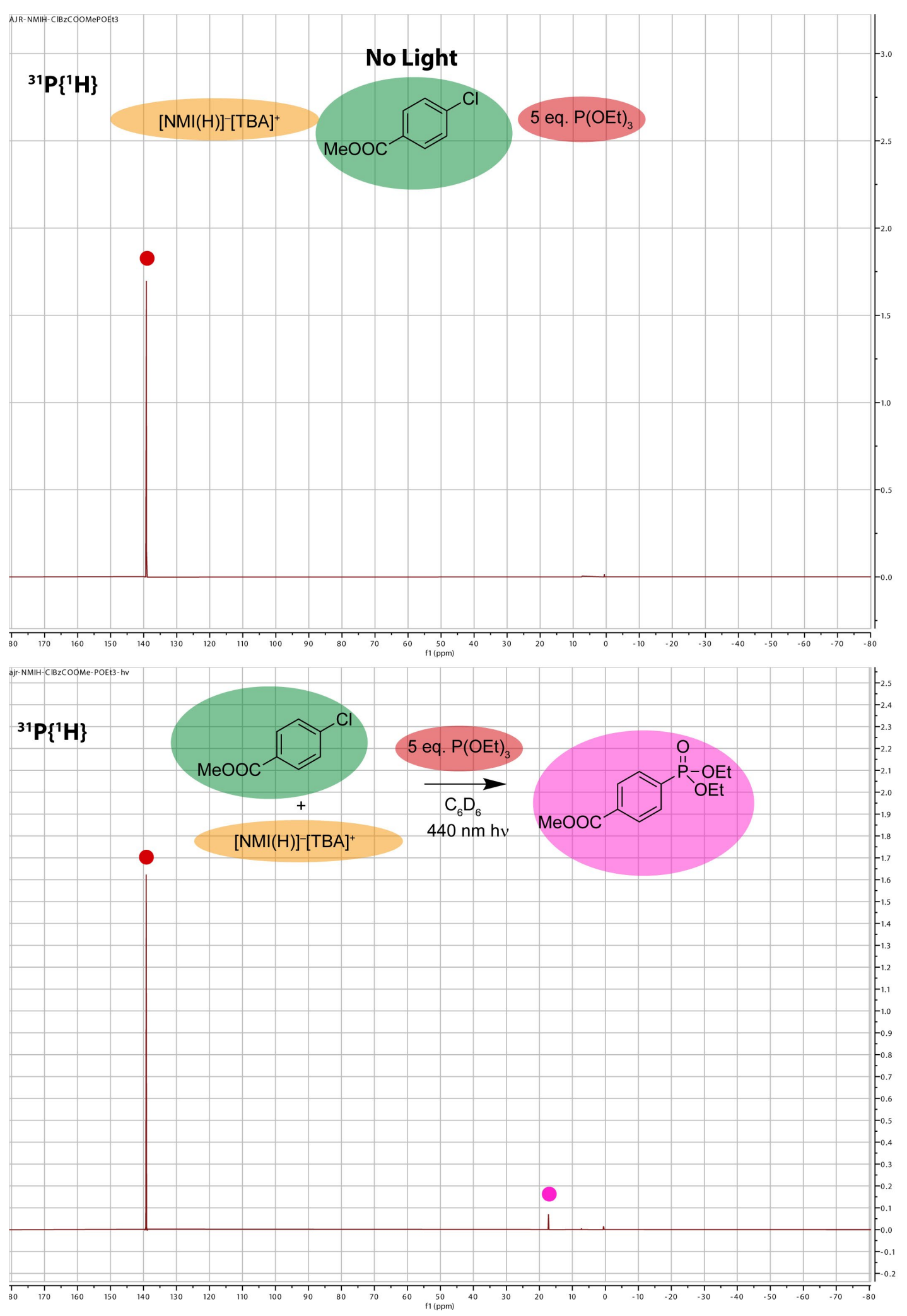

Figure S28. Top: NMR spectrum $\left({ }^{31} \mathrm{P}\left\{{ }^{1} \mathrm{H}\right\}, 400 \mathrm{MHz}\right)$ of $[\mathrm{NMI}(\mathrm{H})]^{-}[\mathrm{TBA}]^{+}$, methyl-4-chlorobenzoate and $\mathrm{P}(\mathrm{OEt})_{3}$ dissolved $\mathrm{C}_{6} \mathrm{D}_{6}$, after sitting in the dark for $2 \mathrm{~h}$ in a J-Young NMR tube. Bottom: NMR spectrum $\left({ }^{31} \mathrm{P}\left\{{ }^{1} \mathrm{H}\right\}, 400 \mathrm{MHz}\right)$ of the same sample after illumination $(440 \mathrm{~nm})$ for $2 \mathrm{~h}$. 


\section{J. References}

1. Cowper, N. G. W.; Chernowsky, C. P.; Williams, O. P.; Wickens, Z. K. Potent Reductants via ElectronPrimed Photoredox Catalysis: Unlocking Aryl Chlorides for Radical Coupling. J. Am. Chem. Soc. 2020, 142, 2093-2099.

2. Bradler, M.; Riedle, E. Temporal and Spectral Correlations in Bulk Continua and Improved Use in Transient Spectroscopy. J. Opt. Soc. Am. B 2014, 31, 1465-1475.

3. SAINT and APEX 2 Software for CCD Diffractometers; Bruker Analytical X-ray Systems: Madison, WI, 2000.

4. Sheldrick, G. M. SADABS; Bruker Analytical X-ray Systems: Madison, WI, 2014.

5. Sheldrick, G. M. SHELXT - Integrated Space-Group and Crystal-Structure Determination. Acta Cryst. A 2015, A71, 3-8.

6. Sheldrick, G. M. SHELXL; University of Göttingen: Germany, 2014.

7. Dolomanov, O. V.; Bourhis, L. J.; Gildea, R. J.; Howard, J. A. K.; Puschmann, H. OLEX2: A Complete Structure Solution, Refinement and Analysis Program. J. Appl. Cryst. 2009, 42, 339-341.

8. Frisch, M. J. et al. Gaussian09 Revision D.01. Gaussian Inc. Wallingford CT 2009.

9. Lee, C.; Yang, W.; Parr, R. G. Development of the Colle-Salvetti correlation-energy formula into a functional of the electron density. Phys. Rev. B 1988, 37, 785-789.

10. Perdew, J. P.; Burke, K.; Ernzerhof, M. Generalized Gradient Approximation Made Simple. Phys. Rev. Lett. 1996, 77, 3865-3868.

11. McLean, A. D.; Chandler, G. S. Contracted Gaussian basis sets for molecular calculations. I. Second row atoms, Z=11-18. J. Chem. Phys. 1980; 72: 5639-48.

12. Krishnan, R.; Binkley, J. S.; Seeger, R.; Pople, J. A. Self-consistent molecular orbital methods. XX. A basis set for correlated wave functions. J. Chem. Phys. 1980, 72, 650-654.

13. Clark, T.; Chandrasekhar, J.; Spitznagel, G. W.; Schleyer, P. V. R. Efficient diffuse function-augmented basis sets for anion calculations. III. The 3-21+G basis set for first-row elements, Li-F. J. Comp. Chem. 1983, 4, 294-301. 
14. Cheeseman, J. R.; Trucks, G. W.; Keith, T. A.; Frisch, M. J. A comparison of models for calculating nuclear magnetic resonance shielding tensors. J. Chem. Phys. 1996, 104, 5497- 5509.

15. Wolinski, K.; Hinton J. F.; Pulay, P. Efficient implementation of the gauge-independent atomic orbital method for NMR chemical shift calculations. J. Am. Chem. Soc. 1990, 112, 8251-8260.

16. Ditchfield, R. Self-consistent perturbation theory of diamagnetism. Mol. Phys. 1974, 27, 789-807.

17. McWeeny, R. Perturbation Theory for the Fock-Dirac Density Matrix. Phys. Rev. 1962, 126, 1028-1034.

18. London, F. Theorie quantique des courants interatomiques dans les combinaisons aromatiques. J. Phys. Radium 1937, 8, 397-409. 